\title{
'Faults detection of a single cracked beam by theoretical and experimental analysis using vibration signatures'
}

\author{
Pankaj Charan Jena ${ }^{1}$, Dayal R. Parhi ${ }^{2}$, Goutam Pohit ${ }^{3}$ \\ ${ }^{l}$ Department of Mechanical Engineering, Orissa Engineering College, Odisha, India, 752050, ${ }^{2}$ Department of \\ Mechanical Engineering, N.I.T. Rourkela, Odisha, India, 769008, ${ }^{3}$ Department of Mechanical Engineering, \\ Jadavpur University. Jadavpur, Kolkata, India,
}

\begin{abstract}
In this work, fault detection in a single cracked beam has been worked out. The identification of location and the depth of crack in a beam containing single transverse crack is done through theoretical and experimental analysis respectively. It has come to noticed that a crack in a beam has great effect on dynamic behavior of beam. The strain energy density function also applied to examine the few more flexibility produced to because of the presence of crack. Considering the flexibility an additional stiffness matrix is taken away and consequently, it is used to find the natural frequency and mode shape of the cracked beam of different end conditions of beam. The difference of mode shapes of cantilever beam, simply supported beam and ClampedClamped beam in between the first three modes of cracked and un-cracked respectively beam with its amplified view at the zone of the crack locale are studied. The theoretical analyses are carried out of the crack structure. Finally for the validation result are compared with the results of both theoretical and experimental analysis. It is found that the contract agreed between their results is excellent.
\end{abstract}

Keywords: beam, crack, fault, frequency, locale, mode shape, stiffness matrix, vibration.

\section{Introduction}

Location of crack through the method of vibration signature is great advantages over traditional methods. Present approach can make it easier to find out the position and crack size of cracked beam structure by the putting of data accumulated from the vibration signature. The crack grew in the structure produces flexibility at the locale of crack which results a contraction of natural frequency and the modification in the mode of shape. From this, it may clear that by measuring and putting the vibration parameters can be calculate the position and depth of the crack of cracked beam. Paris et al. [15] have written the principle for find out of compliance matrix for different types of beams. Sekhar et al. [17] have given a method to calculate the vibration characteristics by applying model based finite element analysis (FEA). Zhu et al. [22] have presented wavelet analysis for crack identification of bridge beam structure under a moving load. Al-Said et al. [1] have developed a mathematical model in which they proposed to identify crack location and depth in a stepped cantilever EulerBernoulli beam carrying a rigid disk at its tip. They have concluded that error in concurrent prediction of crack depth and its location using the proposed algorithm is about 10\%. Xiang et al. [19] have taken a section on beam like structure and developed a model of Rayleigh beam elements model to identify crack location. Chondros et al. [5] have studied the torsion vibration of a circumferentially cracked cylindrical shaft through an exact analytical solution and a numerical finite element analysis. Darpe [7] has projected detection tactic exploits mutually the typical non linear breathing phenomenon of the fault and the coupling of bending torsion vibrations due to the presence of fault for its analysis. He has worked out a transient torsion excitation which is useful for a very small duration at exact angular direction of the rotor and its result in the lateral vibration is investigated. He used wave let transform (WTs) in enlightening the short-lived features of the deep twisting vibrations, which are put conscious for a little duration of time upon transitory torsion excitation. Bachschmid et al. [3] have studied develop of fatigue cracks in rotating shaft and explained their propagation was mainly in planes perpendicular to the axis of rotation. Qiao et al. [16] have presented sign form fractal dimension for mode shape-based break identification of beam -type structures. In their work they used to differentiate in between the popular Katz's wave form fractal dimension (KWD) and an approximate wave form capacity dimension (AWCD). Arsit [4] has studied and developed a model based technique for cracked rotor vibration system and implemented and concluded with identification of crack, location and depth of crack in rotating machinery. Faverjon et al. [10] have applied constitutive error updating method to identification of cracks location and size in a simply supported beam. Chandan et al. [13] have explained rotor fault through various methods and explained using Lagragian formulation to examine cracked rotor through nonlinear dynamics. Lu et al. [14] have applied a response sensitivity-based approach of damage identification. El- Ouafi et al. [9] have proposed damage identification method. They have worked out to defect and locate damage, which is validated experimentally through ambient vibration tests conducted on full scale reinforced concrete beams and slabs with having various simple and multiple damage configurations. Das et al. [8] have used a soft computing fuzzy-logic approach for 
crack identification in a cantilever beam. They have used Gaussian membership functions in strain energy release rate and fuzzy controller to find out the local stiff nesses at crack location of the beam. Gardoni [11] has developed an additive reliability analysis of reinforced concrete bridges incorporating the damage detection information obtained from non destructive testing (NDT). He used Seismic fragility to describe the reliability of a structure with standing future seismic demand. Chondros [6] has calculated the fatigue crack propagation of repeated loading of the outer strut leg of the Bjork - shiley $60^{\circ}$ convexo-concave (BSCC) valve with a range of time from a few months to few years. He concluded that sound emitted from the strut of the valve due to impact may be used to monitor the propagation of the fatigue crack before it would lead to failure of the one or both legs of the outlet strut. Kim et al. [12] have worked to identify structural damage of a cantilever beam using excitation force level control. Singh et al. [18] have used transverse frequency response functions by genetic algorithm method to identification of a multi crack in a shaft system. In his work, he has reduced the effect of noise of shaft by utilizing force responses in GA method. Zhong et al. [21] have proposed a new approach for damage detection in beam like structures with small cracks whose crack ratio $=\left(\mathrm{H}_{\mathrm{c}} / \mathrm{H}\right)<5 \%$ without baseline modal parameters. Andreaus et al. [2] have used numerical analysis the nonlinear behavior of the harmonically forced response to identification of cracked beam. They have applied phase portrait distortions and Fourier spectrum to sub and super harmonic components. Yan et al. [20] have worked on Statistic structural damage recognition based on the closed-form of element modal strain energy sensitivity.

The aim of this paper is especially on the problem of crack detection for a cracked beam using theoretical analysis and experimental analysis. The approach evolved in this paper intimates location, size and depth of the open crack in beam of different end conditions with rectangular cross sect: $(a)$. The comparison results in both methodologies are written above are performed. The results of the (a)...ical analysis and experimental analysis are compared

\section{2. Theoretical Analysis}

2.1 Local flexibility of a cracked beam under bending and axial loading:

A cantilever beam of length ' $\mathrm{L}$ ', width ' $\mathrm{B}$ ' and thickness ' $\mathrm{W}$ ' is bearing a transverse surface crack of depth ' $a_{1}$ ' with distance ' $L_{1}$ ' from its fixed support and leads into a local flexibility, which can be expressed in matrix form by using all dimensions of which depends on the degrees of freedom. At present a $2 \times 2$ matrix is carried out. Cantilever beam is subjected to axial force ' $\mathrm{P}_{1}$ ' and bending moment ' $\mathrm{P}_{2}$ ', shown in figure 1(a), which gives coupling with the longitudinal and transverse motion. The cross sectional view of beam is in figure $1(b)$.

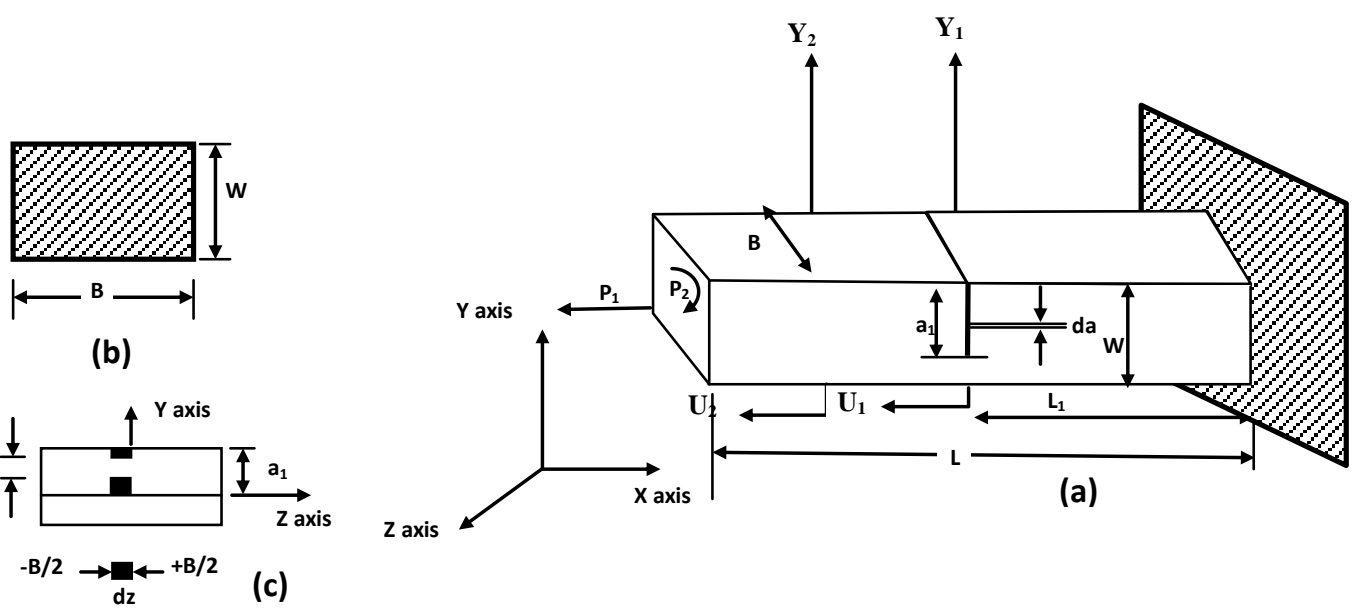

Figure: 1 Geometry of beam (a) cantilever beam (b) cross-sectional view of the beam (c) crack depth and position.

The strain energy release rate at the fractured section can be written as [15]

$\mathrm{J}=\frac{1}{E^{\prime}}\left(\mathrm{K}_{11}+\mathrm{K}_{12}\right)^{2}$

The stress intensity factors are $\mathrm{K}_{11}, \mathrm{~K}_{12}$ of mode $\mathrm{I}$ (opening of the crack) under load $\mathrm{P}_{1}$ and $\mathrm{P}_{2}$ respectively. The ideals of stress concentration factors from earlier studies are (Paris et al. [15]);

$\mathrm{K}_{\mathrm{I} 1}=\frac{\mathrm{P}_{1}}{\mathrm{BW}} \sqrt{\pi \mathrm{a}}\left(\mathrm{F}_{1}\left(\frac{\mathrm{a}}{\mathrm{W}}\right)\right), \mathrm{K}_{\mathrm{I} 2}=\frac{6 \mathrm{P}_{2}}{\mathrm{BW}^{2}} \sqrt{\pi \mathrm{a}}\left(\mathrm{F}_{2}\left(\frac{\mathrm{a}}{\mathrm{W}}\right)\right)$ 
Let $U_{t}$ be the strain energy caused by crack. Since Castiglione's theorem, the further displacement all along the force $P_{i}$ is: $u_{i}=\frac{\partial U_{t}}{\partial P_{i}}$

The strain energy will have the shape of, $U_{t}=\int_{0}^{a_{1}} \frac{\partial U_{t}}{\partial a} d a=\int_{0}^{a_{1}} J d a$

Where $\mathrm{J}=\frac{\partial \mathrm{U}_{\mathrm{t}}}{\partial \mathrm{a}}$, the strain energy density function.

From equations (3) and (4), $\mathrm{u}_{\mathrm{i}}=\frac{\partial}{\partial \mathrm{P}_{\mathrm{i}}}\left[\int_{0}^{\mathrm{a}_{1}} \mathrm{~J}(\mathrm{a}) \mathrm{da}\right]$

$\mathrm{C}_{\mathrm{ij}}=\frac{\partial \mathrm{u}_{\mathrm{i}}}{\partial \mathrm{P}_{\mathrm{j}}}=\frac{\partial^{2}}{\partial \mathrm{P}_{\mathrm{i}} \partial \mathrm{P}_{\mathrm{j}}} \int_{0}^{\mathrm{a}_{1}} \mathrm{~J}(\mathrm{a}) \mathrm{da}$

To set the concluding flexibility matrix integrate over the breadth ' $\mathrm{B}$ '

$\mathrm{C}_{\mathrm{ij}}=\frac{\partial \mathrm{u}_{\mathrm{i}}}{\partial \mathrm{P}_{\mathrm{j}}}=\frac{\partial^{2}}{\partial \mathrm{P}_{\mathrm{i}} \partial \mathrm{P}_{\mathrm{j}}} \int_{-\mathrm{B} / 2}^{+\mathrm{B} / 2} \int_{0}^{\mathrm{a}_{1}} \mathrm{~J}(\mathrm{a}) \mathrm{dadz}$

Using strain energy release rate from above $C_{i j}=\frac{B}{E^{\prime}} \frac{\partial^{2}}{\partial P_{i} \partial P_{j}} \int_{0}^{a_{1}}\left(K_{11}+K_{12}\right)^{2} d a$

Put $\xi=(a / w), d \xi=\frac{d a}{W}$ We get $d a=W d \xi$ and when $a=0, \xi=0 ; a=a_{1}, \xi=a_{1} / W=\xi{ }_{1}$ From the above condition, $\mathrm{C}_{\mathrm{ij}}=\frac{\mathrm{BW}}{\mathrm{E}^{\prime}} \frac{\partial^{2}}{\partial \mathrm{P}_{\mathrm{i}} \partial \mathrm{P}_{\mathrm{j}}} \int_{0}^{\xi_{1}}\left(\mathrm{~K}_{11}+\mathrm{K}_{12}\right)^{2} \mathrm{~d} \xi$

The local stiffness matrix can be obtained by taking the inversion of observance matrix.

$\mathrm{K}=\left[\begin{array}{ll}\mathrm{K}_{11} & \mathrm{~K}_{12} \\ \mathrm{~K}_{21} & \mathrm{~K}_{22}\end{array}\right]=\left[\begin{array}{ll}\mathrm{C}_{11} & \mathrm{C}_{12} \\ \mathrm{C}_{21} & \mathrm{C}_{22}\end{array}\right]^{-1}$

Figure 2 is the variation of dimensionless compliances to that of relative crack depth.

Series $1=\mathrm{C}_{11}$

Series $2=\mathrm{C}_{12}=\mathrm{C}_{21}$

Series $3=\mathrm{C}_{22}$

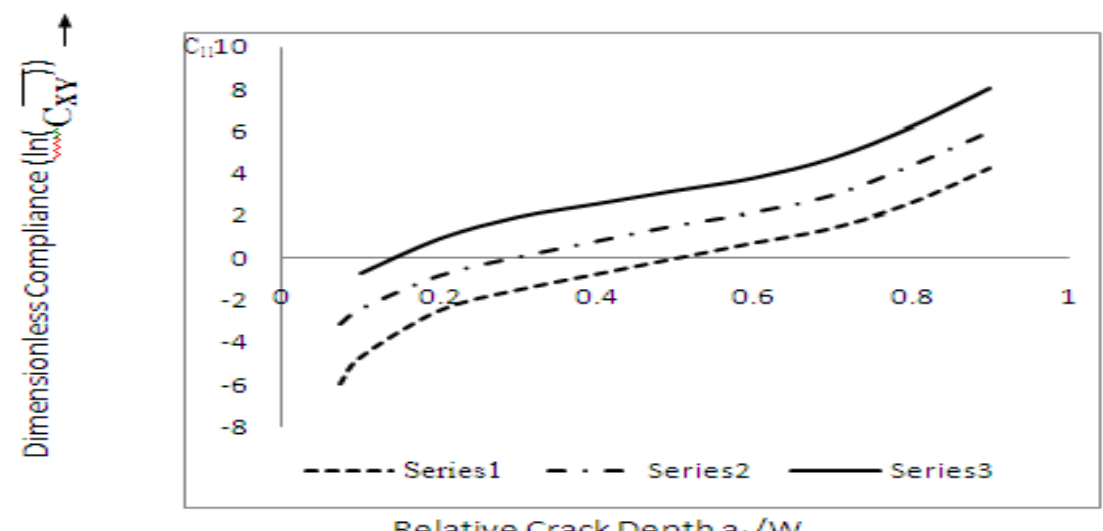

Figure: 2 Relative crack depth $\left(a_{1} / w\right)$ vs. dimensionless compliance $\left(\operatorname{In}\left(\overline{\mathrm{C}_{x y}}\right)\right)$ 


\subsection{Analysis of Free Vibration Characteristics of the Cracked Beam:}

A cantilever beam of length ' $L$ ' width ' $B$ ' and depth ' $W$ ', with a crack of depth ' $a_{1}$ ' at a distance ' $L_{1}$ ' from the fixed end is considered. Taking $\mathrm{u}_{1}(\mathrm{x}, \mathrm{t})$ and $\mathrm{u}_{2}(\mathrm{x}, \mathrm{t})$ are amplitudes of longitudinal vibration for the sections before and after the crack and $y_{1}(x, t), y_{2}(x, t)$ are the amplitudes of bending vibration for the same sections as shown in figure 1.The standard function for the arrangement can be described as

$$
\begin{aligned}
& \overline{\mathrm{u}}_{1}(\overline{\mathrm{x}})=\mathrm{A}_{1} \cos \left(\overline{\mathrm{K}}_{\mathrm{u}} \overline{\mathrm{x}}\right)+\mathrm{A}_{2} \sin \left(\overline{\mathrm{K}}_{\mathrm{u}} \overline{\mathrm{x}}\right) \\
& \overline{\mathrm{u}}_{2}(\overline{\mathrm{x}})=\mathrm{A}_{3} \cos \left(\overline{\mathrm{K}}_{\mathrm{u}} \overline{\mathrm{x}}\right)+\mathrm{A}_{4} \sin \left(\overline{\mathrm{K}}_{\mathrm{u}} \overline{\mathrm{x}}\right) \\
& \overline{\mathrm{y}}_{1}(\overline{\mathrm{x}})=\mathrm{A}_{5} \cosh \left(\overline{\mathrm{K}}_{\mathrm{y}} \overline{\mathrm{x}}\right)+\mathrm{A}_{6} \sinh \left(\overline{\mathrm{K}}_{\mathrm{y}} \overline{\mathrm{x}}\right)+\mathrm{A}_{7} \cos \left(\overline{\mathrm{K}}_{\mathrm{y}} \overline{\mathrm{x}}\right)+\mathrm{A}_{8} \sin \left(\overline{\mathrm{K}}_{\mathrm{y}} \overline{\mathrm{x}}\right) \\
& \overline{\mathrm{y}}_{2}(\overline{\mathrm{x}})=\mathrm{A}_{9} \cosh \left(\overline{\mathrm{K}}_{\mathrm{y}} \overline{\mathrm{x}}\right)+\mathrm{A}_{10} \sinh \left(\overline{\mathrm{K}}_{\mathrm{y}} \overline{\mathrm{x}}\right)+\mathrm{A}_{11} \cos \left(\overline{\mathrm{K}}_{\mathrm{y}} \overline{\mathrm{x}}\right)+\mathrm{A}_{12} \sin \left(\overline{\mathrm{K}}_{\mathrm{y}} \overline{\mathrm{x}}\right)
\end{aligned}
$$

Where, $\overline{\mathrm{u}}=\frac{\mathrm{u}}{\mathrm{L}}, \overline{\mathrm{x}}=\frac{\mathrm{x}}{\mathrm{L}}, \overline{\mathrm{y}}=\frac{\mathrm{y}}{\mathrm{L}}, \beta=\frac{\mathrm{L}_{1}}{\mathrm{~L}}$

$$
\overline{\mathrm{K}}_{\mathrm{u}}=\frac{\omega \mathrm{L}}{\mathrm{C}_{\mathrm{u}}}, \overline{\mathrm{K}}_{\mathrm{y}}=\left(\frac{\omega \mathrm{L}^{2}}{\mathrm{C}_{\mathrm{y}}}\right)^{1 / 2}, \mathrm{C}_{\mathrm{u}}=\left(\frac{\mathrm{E}}{\rho}\right)^{1 / 2}, \mathrm{C}_{\mathrm{y}}=\left(\frac{\mathrm{EI}}{\mu}\right)^{1 / 2}, \mu=\mathrm{A} \rho
$$

$A_{i},(i=1,2)$ Constants are to be estimate, from particular limit conditions. The limit conditions of the cantilever beam in consideration are:

$$
\overline{\mathrm{u}}_{1}(0)=0 ; \quad \bar{y}_{1}(0)=0 ; \quad \bar{y}_{1}^{\prime}(0)=0 ; \quad \overline{\mathrm{u}}_{2}^{\prime}(1)=0 ; \quad \overline{\mathrm{y}}_{2}^{\prime \prime}(1)=0 ; \quad \overline{\mathrm{y}}_{2}^{\prime \prime \prime}(1)=0
$$

At the cracked section:

$$
\overline{\mathrm{u}}_{1}(\beta)=\overline{\mathrm{u}}_{2}(\beta) ; \overline{\mathrm{y}}_{1}(\beta)=\overline{\mathrm{y}}_{2}(\beta) ; \overline{\mathrm{y}}_{1}^{\prime \prime}(\beta)=\overline{\mathrm{y}}_{2}^{\prime \prime}(\beta) ; \overline{\mathrm{y}}_{1}^{\prime \prime \prime}(\beta)=\overline{\mathrm{y}}_{2}^{\prime \prime \prime}(\beta)
$$

Also at the cracked section at distance $\mathrm{L}_{1}$ from fixed end of cantilever bar, we obtain,

$$
\mathrm{AE} \frac{\mathrm{du}_{1}\left(\mathrm{~L}_{1}\right)}{\mathrm{dx}}=\mathrm{K}_{11}\left(\mathrm{u}_{2}\left(\mathrm{~L}_{1}\right)-\mathrm{u}_{1}\left(\mathrm{~L}_{1}\right)\right)+\mathrm{K}_{12}\left(\frac{\mathrm{dy}_{2}\left(\mathrm{~L}_{1}\right)}{\mathrm{dx}}-\frac{\mathrm{dy}_{1}\left(\mathrm{~L}_{1}\right)}{\mathrm{dx}}\right)
$$

Multiplying each side of the equation (15) by $\frac{\mathrm{AE}}{\mathrm{LK}_{11} \mathrm{~K}_{12}}$ we obtain

$$
\mathrm{M}_{1} \mathrm{M}_{2} \overline{\mathrm{u}}^{\prime}(\beta)=\mathrm{M}_{2}\left(\overline{\mathrm{u}}_{2}(\beta)-\overline{\mathrm{u}}_{1}(\beta)\right)+\mathrm{M}_{1}\left(\overline{\mathrm{y}}_{2}^{\prime}(\beta)-\overline{\mathrm{y}}_{1}^{\prime}(\beta)\right)
$$

Similarly, EI $\frac{\mathrm{d}^{2} \mathrm{y}_{1}\left(\mathrm{~L}_{1}\right)}{\mathrm{dx}^{2}}=\mathrm{K}_{21}\left(\mathrm{u}_{2}\left(\mathrm{~L}_{1}\right)-\mathrm{u}_{1}\left(\mathrm{~L}_{1}\right)\right)+\mathrm{K}_{22}\left(\frac{\mathrm{dy}_{2}\left(\mathrm{~L}_{1}\right)}{\mathrm{dx}}-\frac{\mathrm{dy}_{1}\left(\mathrm{~L}_{1}\right)}{\mathrm{dx}}\right)$

Multiplying each side of the equation (17) by $\frac{E I}{\mathrm{~L}^{2} \mathrm{~K}_{22} \mathrm{~K}_{21}}$ we obtain,

$\mathrm{M}_{3} \mathrm{M}_{4} \overline{\mathrm{y}}_{1}^{\prime \prime}(\beta)=\mathrm{M}_{3}\left(\overline{\mathrm{u}}_{2}(\beta)-\overline{\mathrm{u}}_{1}(\beta)\right)+\mathrm{M}_{4}\left(\overline{\mathrm{y}}_{2}^{\prime}(\beta)-\overline{\mathrm{y}}_{1}^{\prime}(\beta)\right)$

Where, $M_{1}=\frac{A E}{L_{11}}, M_{2}=\frac{A E}{K_{12}}, M_{3}=\frac{E I}{L_{22}}, M_{4}=\frac{E I}{L^{2} K_{21}}$

The normal functions, equation (11) along with the boundary conditions as mentioned above, yield the characteristic equation of the system as: $|\mathrm{Q}|=0$

This determinant is a function of natural circular frequency $(\omega)$, the relative location of the crack $(\beta)$ and the local stiffness matrix $(K)$ which in turn is a function of the relative crack depth $\left(\mathrm{a}_{1} / \mathrm{W}\right)$.

2.3. Analysis for Beams

To determine the differential equation for lateral vibration of beam, consider the forces and moments acting on an element of the beam shown in figure 4. 


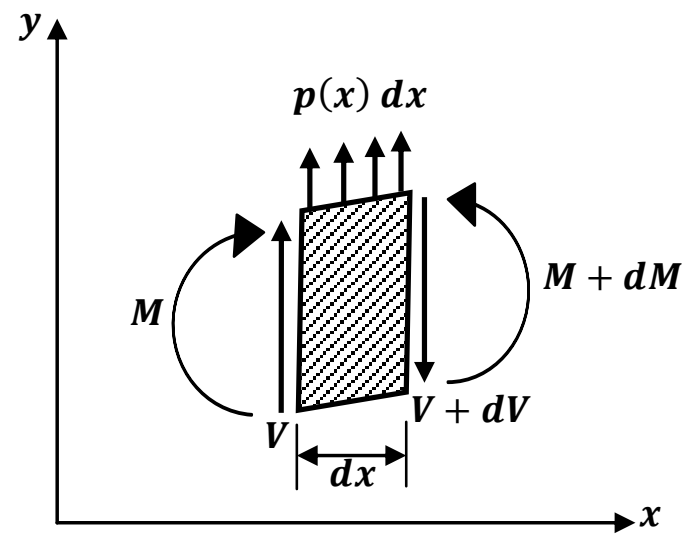

(Figure: 3 the shear forces and moments stand-on an element of the beam.) beam.

Let, $\mathrm{V}$ and $\mathrm{M}$ are shear and bending moments, and $P(x)$ represents the loading per unit length of the

in Y-direction, $\mathrm{d} V-P(x) \mathrm{dx}=0$

Sum of moments about any point on the right face of the element,

$\mathrm{dM}-V \mathrm{dx}-P(x) \mathrm{dx}(\mathrm{dx} / 2)=0$

Hence, $\mathrm{dM}-V \mathrm{dx}-1 / 2\left[P(x)(\mathrm{dx})^{2}\right]$

Here limiting procedure gives following important relationships,

$\frac{d V}{d x}=P(x), \frac{d M}{d x}=V$

From equation (21), we obtain $\frac{d^{2} M}{d x^{2}}=\frac{d V}{d x}=P(x)$

The bending moment $M=E I \frac{d^{2} Y}{d x^{2}}$,

So, the equation (22) will be $\frac{d^{2}}{d x^{2}}\left(E I \frac{d^{2} Y}{d x^{2}}\right)=P(x)$

For a beam vibrating about its static equilibrium position under its weight, the weight per element span is equal to the inertia load due to its mass and acceleration. Since the inertia force is the same direction as $P(x)$, by harmonic motion,

$P(x)=\rho \omega^{2} y$

Using this relation, the equation for the lateral vibration of the beam reduces to

$\frac{d^{2}}{d x^{2}}\left(E I \frac{d^{2} Y}{d x^{2}}\right)-\rho \omega^{2} y=0$

In the special case where the flexural rigidity $E I$ is constant, the above equation may be written as, $\left(E I \frac{d^{4} Y}{d x^{4}}\right)-$ $\rho \omega^{2} y=0$

We obtain the fourth- order differential equation, $\frac{d^{4} Y}{d x^{4}}-\alpha^{\mathbf{4}} y=0$

For the vibration of a uniform beam, the general solution of equation (27) can be shown $Y=A \cosh \alpha x+$ $B \sinh \alpha x+C \cos \alpha x+D \sin \alpha x$

Case 1: Natural frequencies of vibration of a uniform cantilever beam

The boundary conditions: at $x=0,\left\{\begin{array}{l}y=0 \\ \frac{d y}{d x}=0\end{array}, x=L, \begin{cases}M=0 & \text { or, } \frac{d^{2} y}{d x^{2}}=0 \\ V=0 & \text { or, } \frac{d^{3} y}{d x^{3}}=0\end{cases}\right.$ 


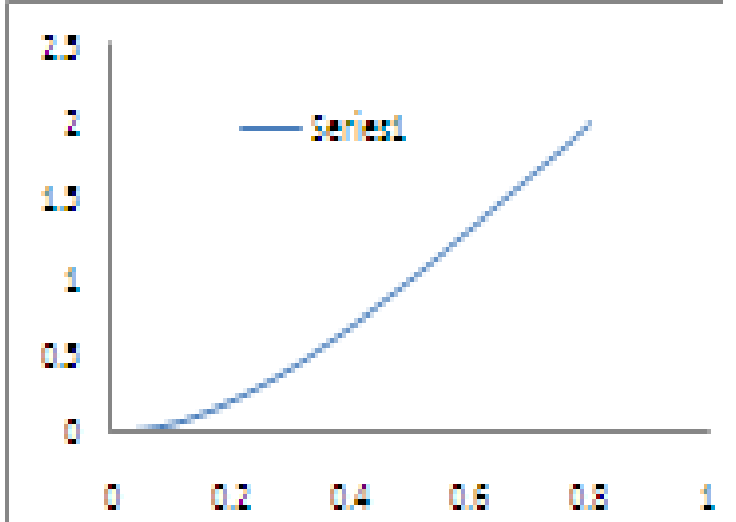

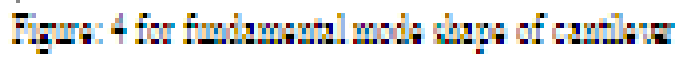
bam whow arak

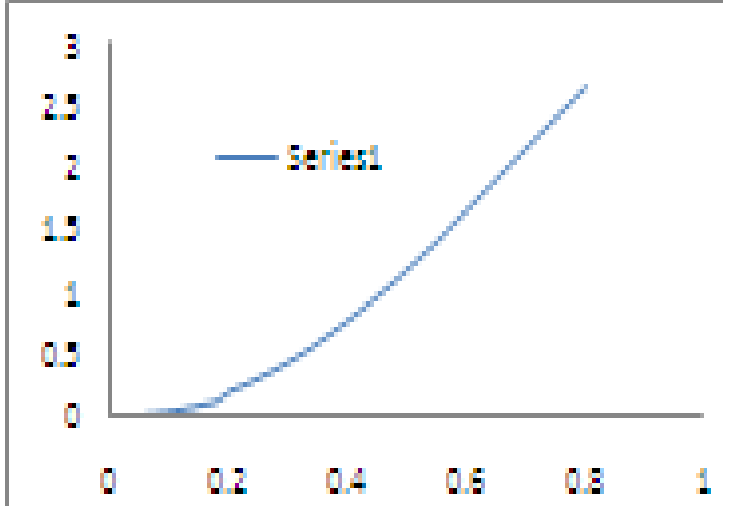

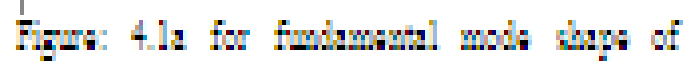

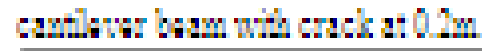

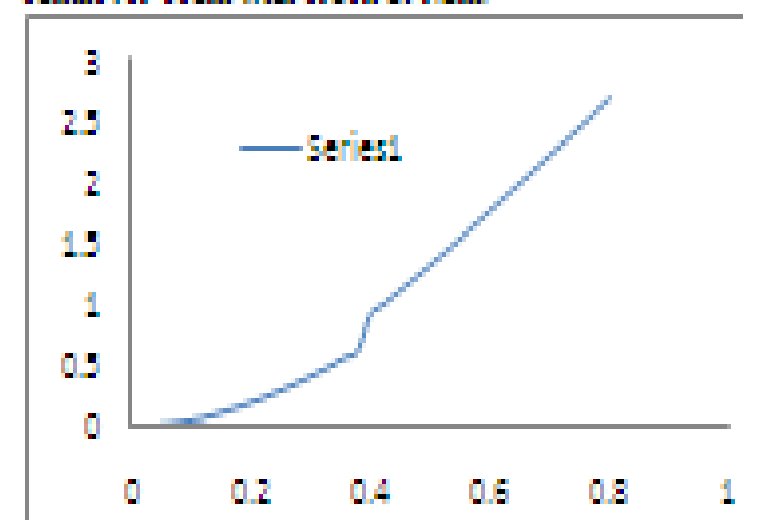

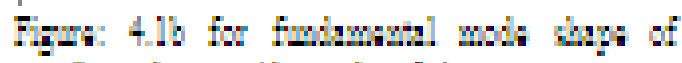

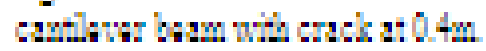

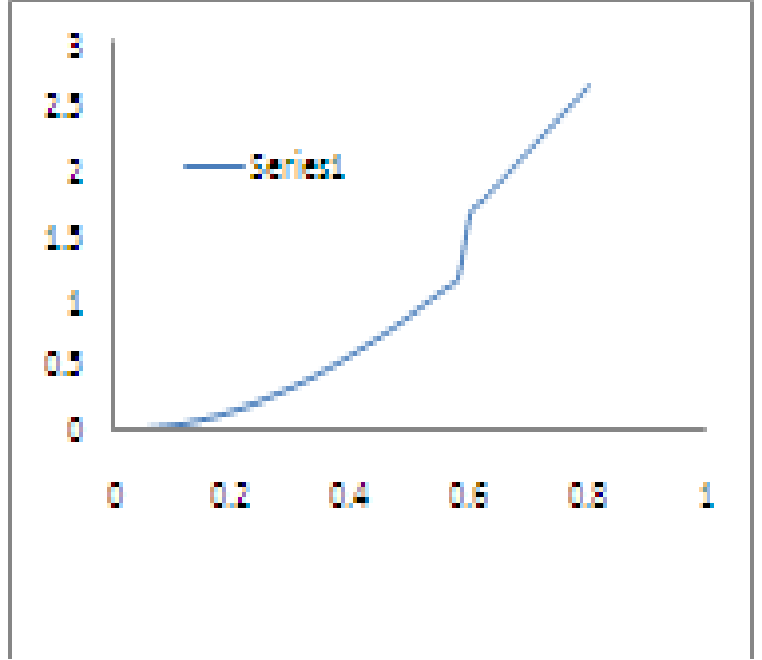

Fere: 4le for frimast wols bays of caxtina bam wh wak atom

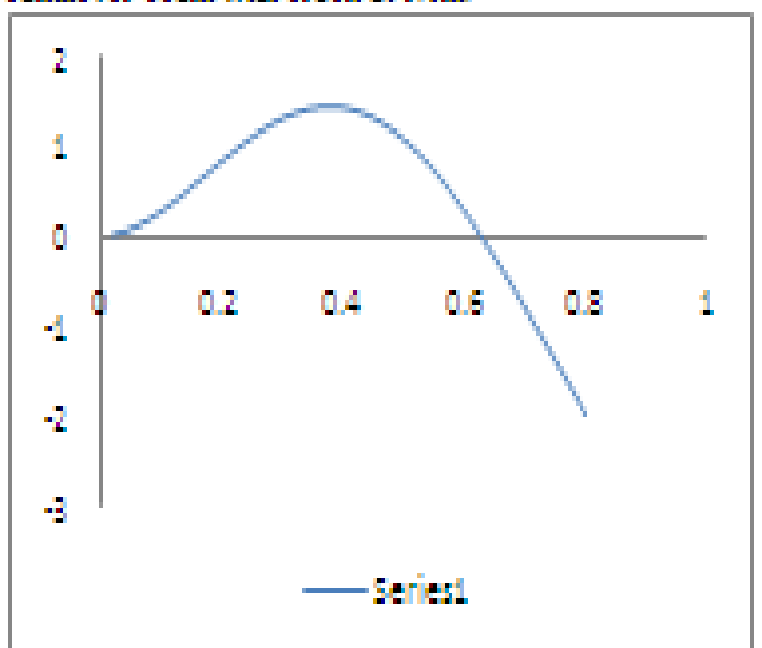

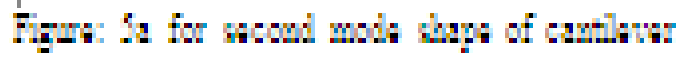
baw when and

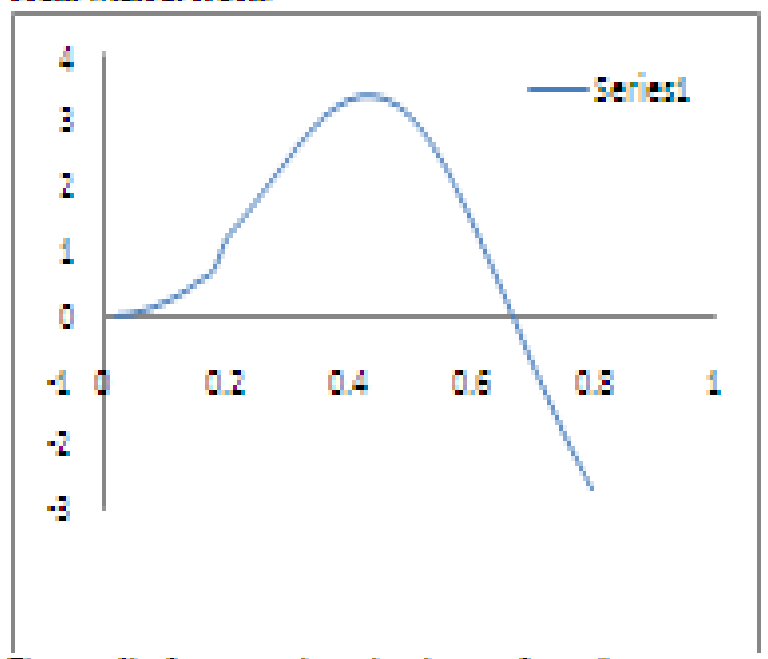

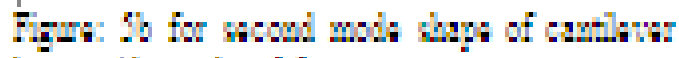

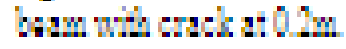



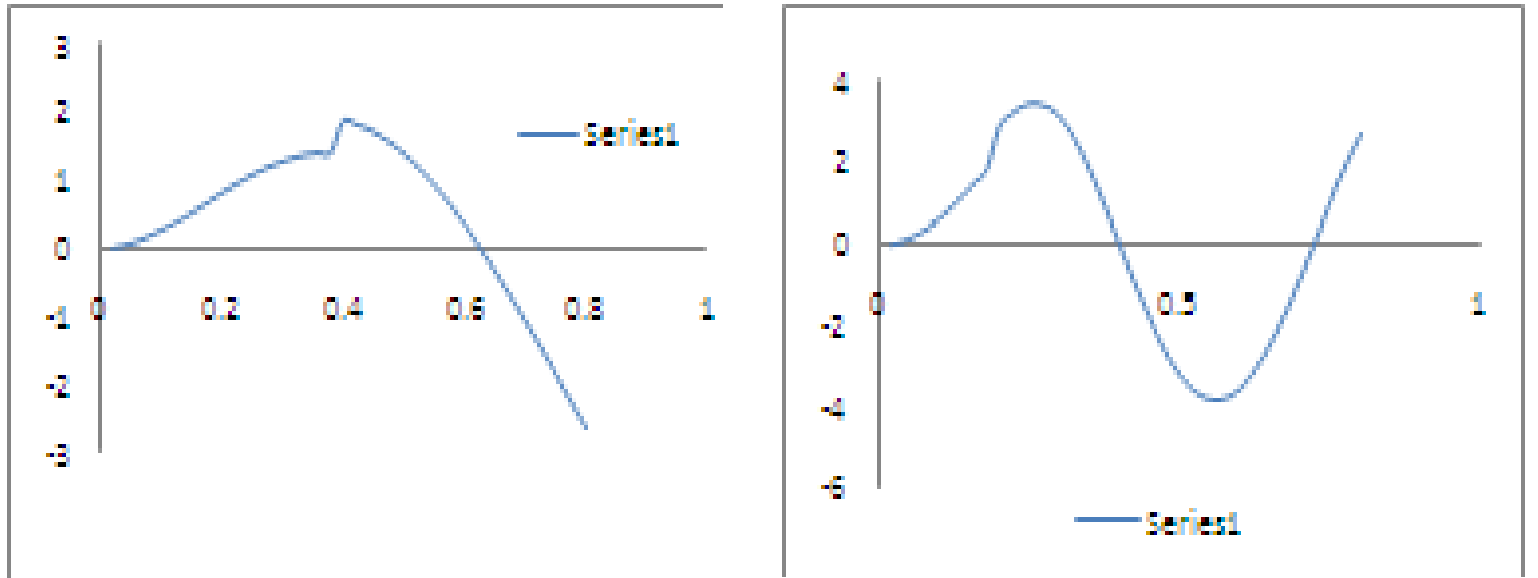

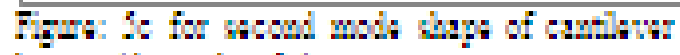
bam wht arak at 0.4m.

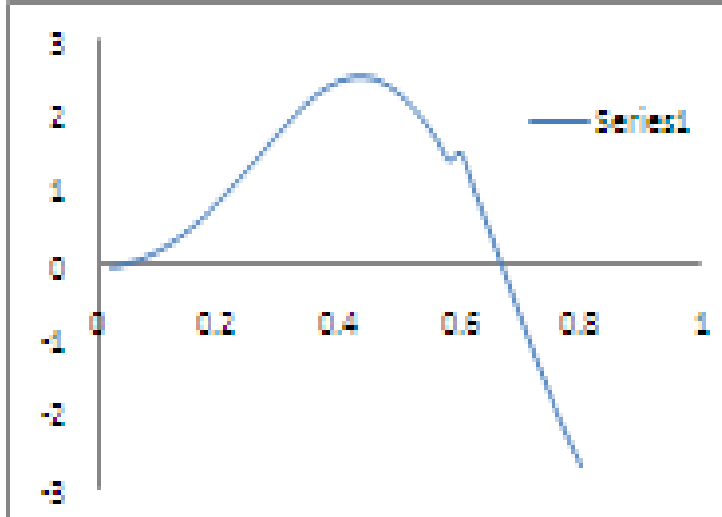

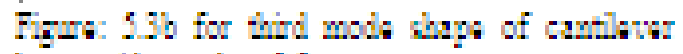
bam wh wak a:07m

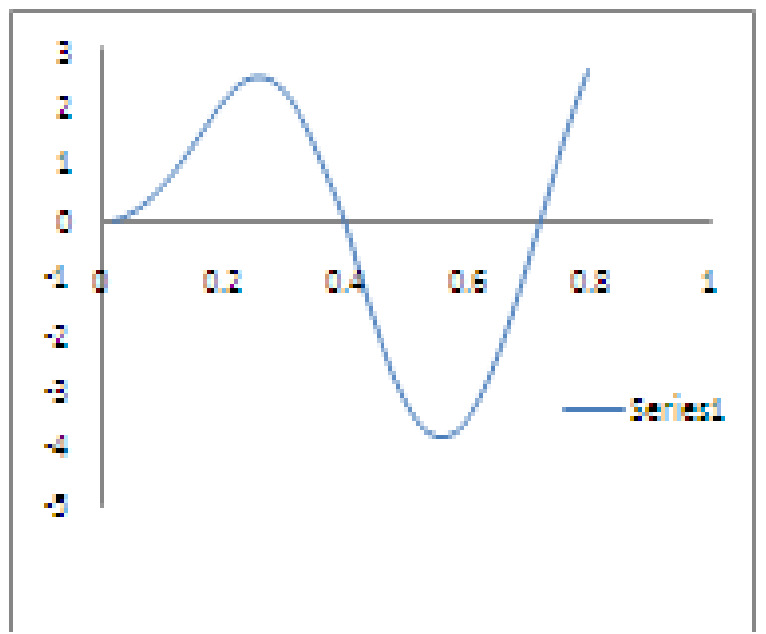

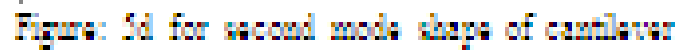
baw wh waka a.6.

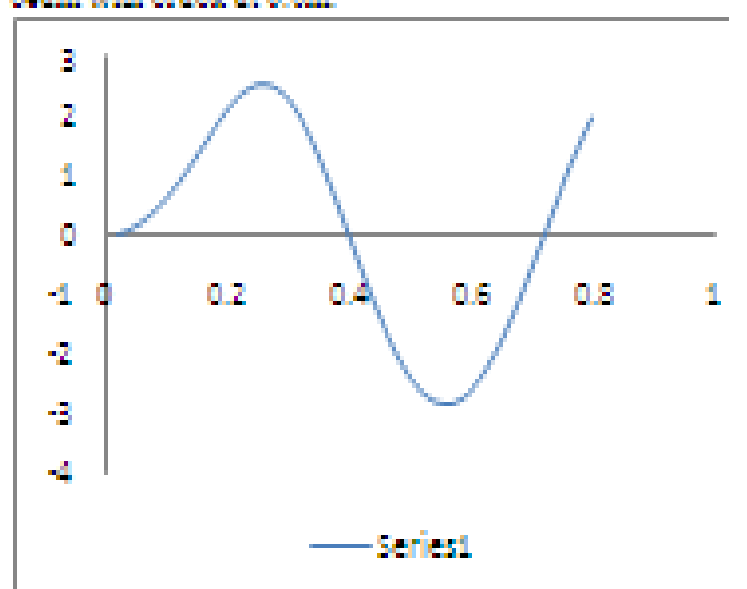

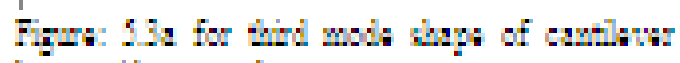
bam othore oratk

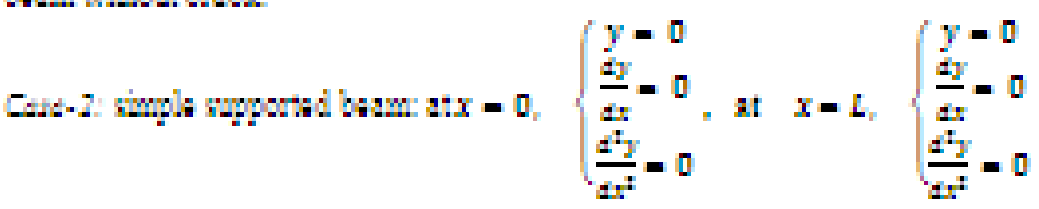

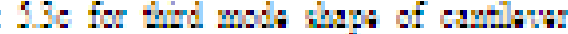
an wh erak a: 0.4m

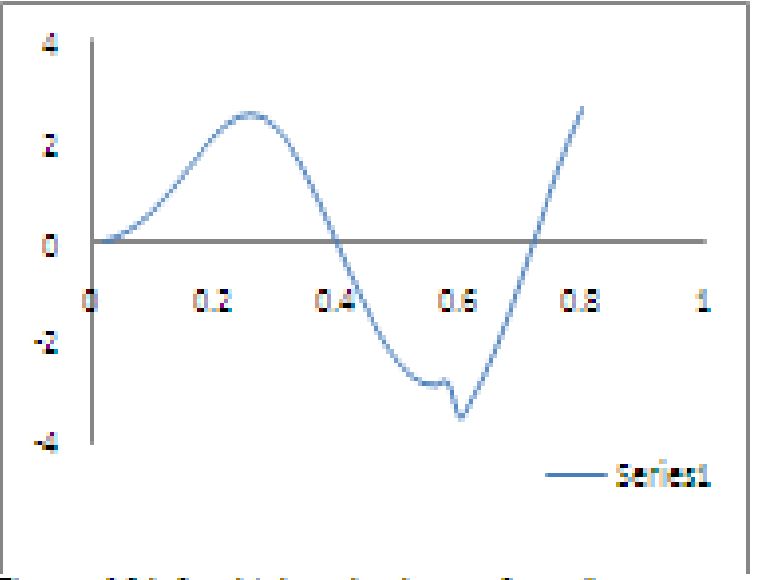

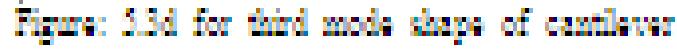
bam wh orak at 06m 


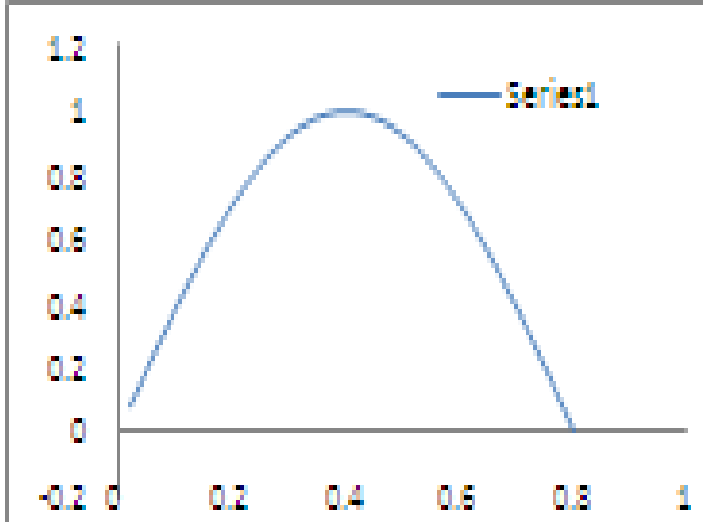

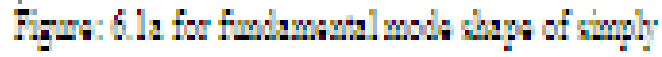
hil w riform ban who wat

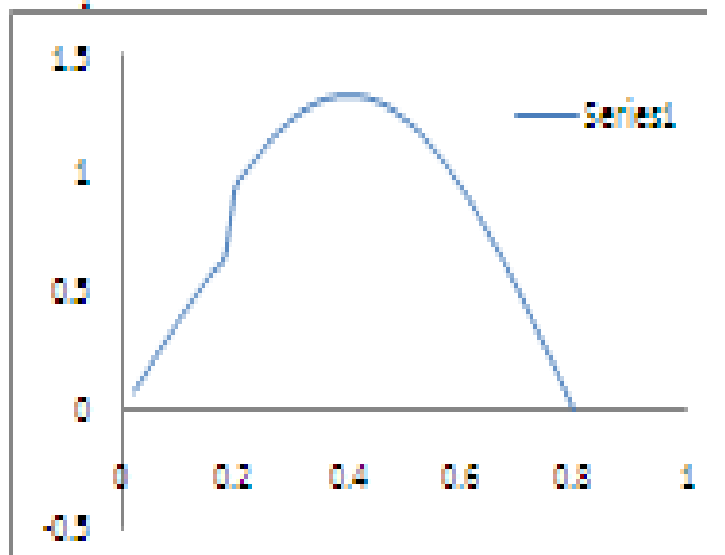

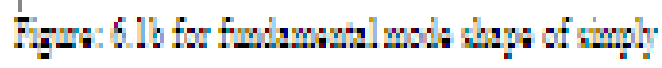
hid reform bum at:olm

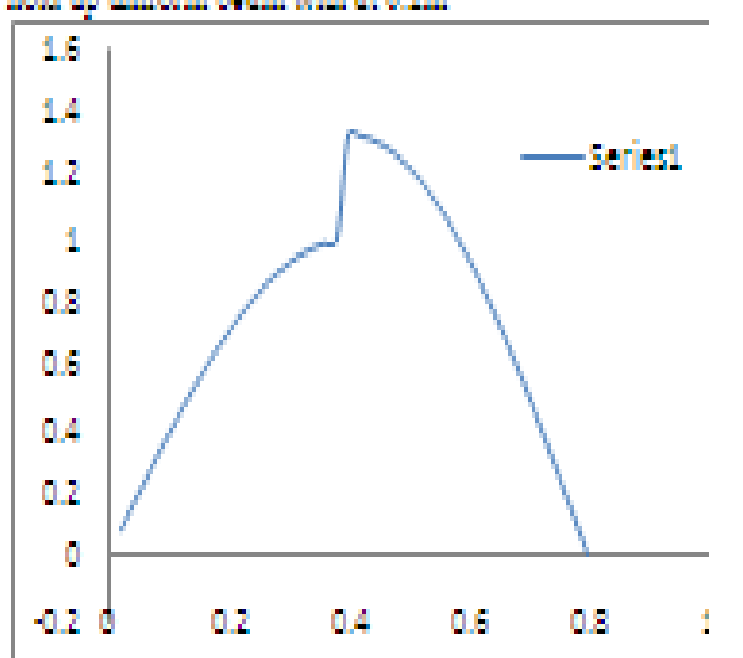

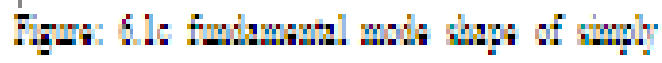

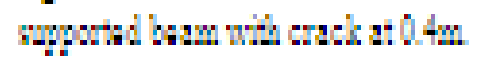

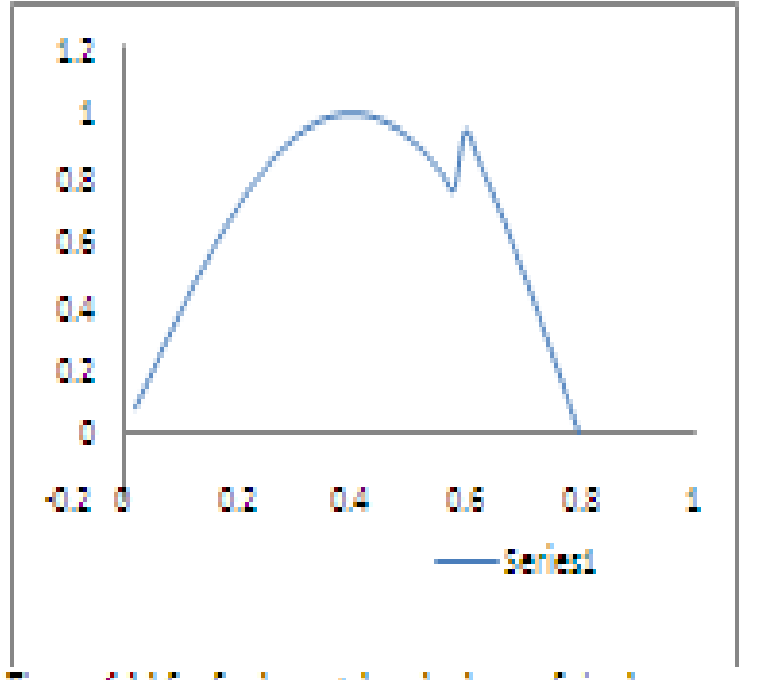

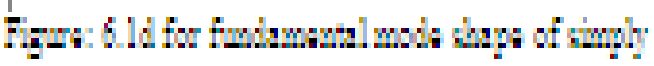

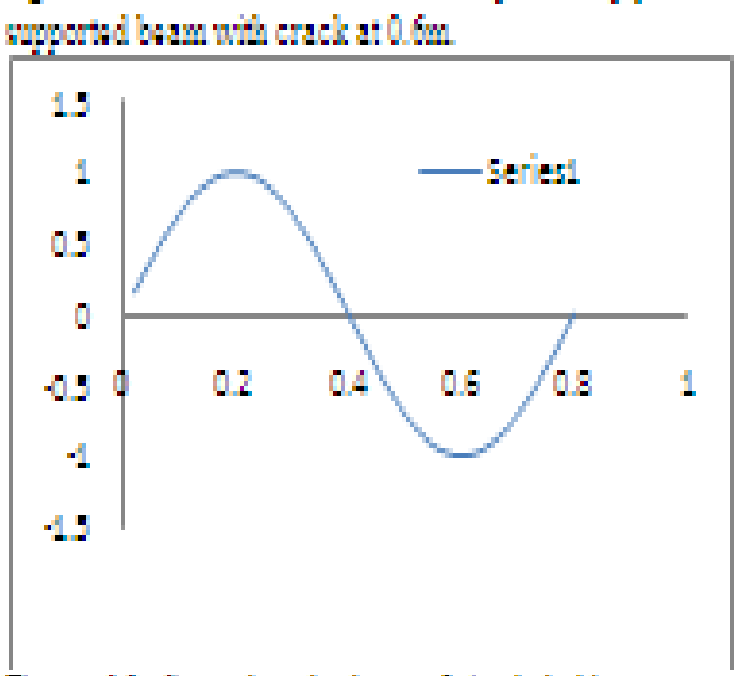

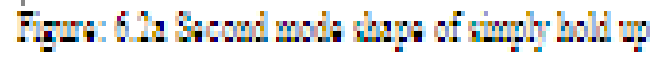

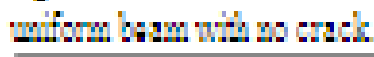

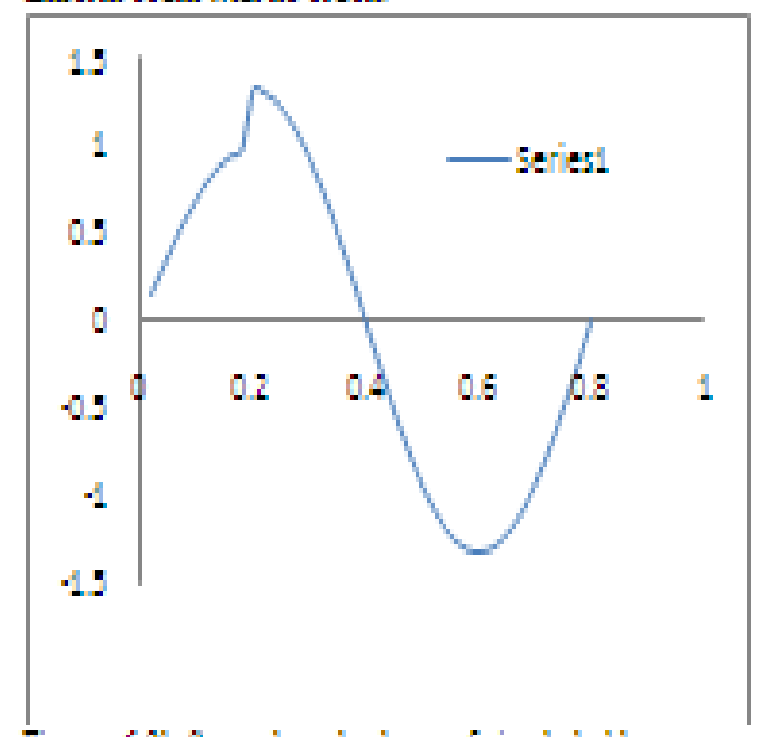

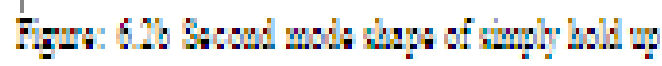
ciform bam wh wak ato.m 


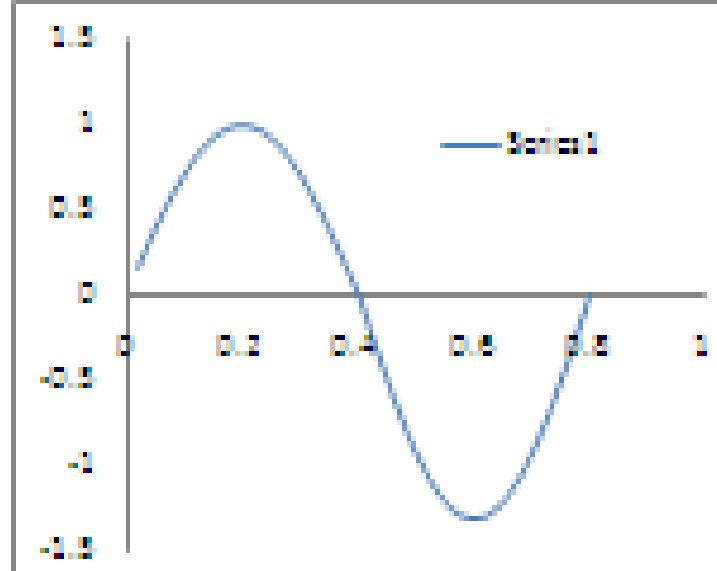

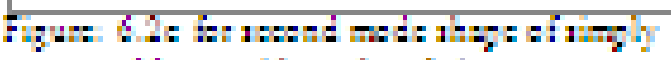

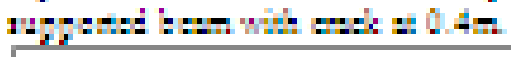

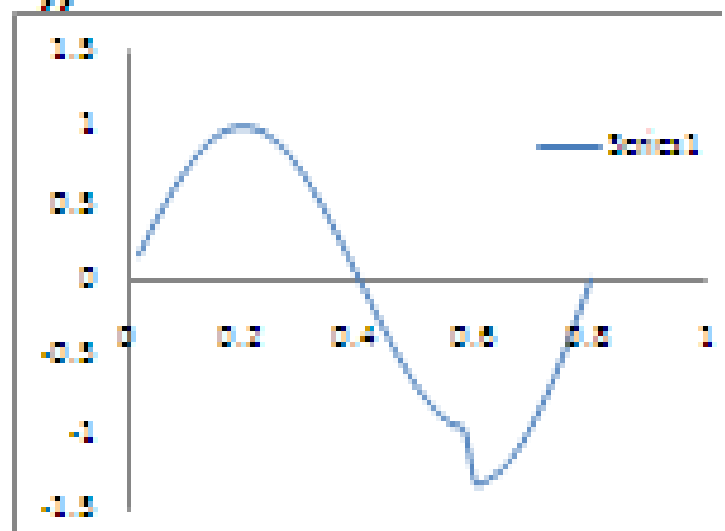

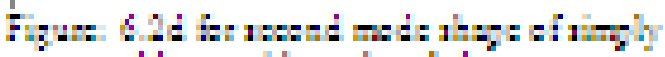

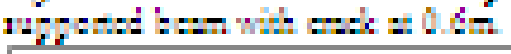

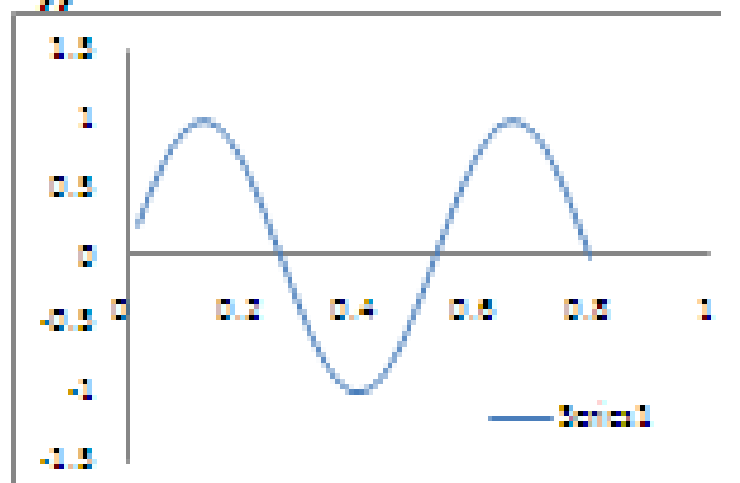

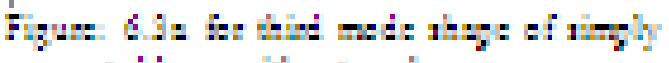

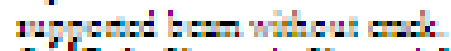

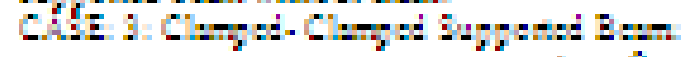

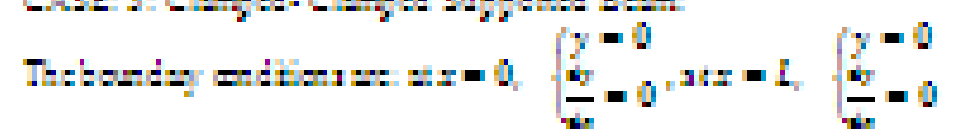

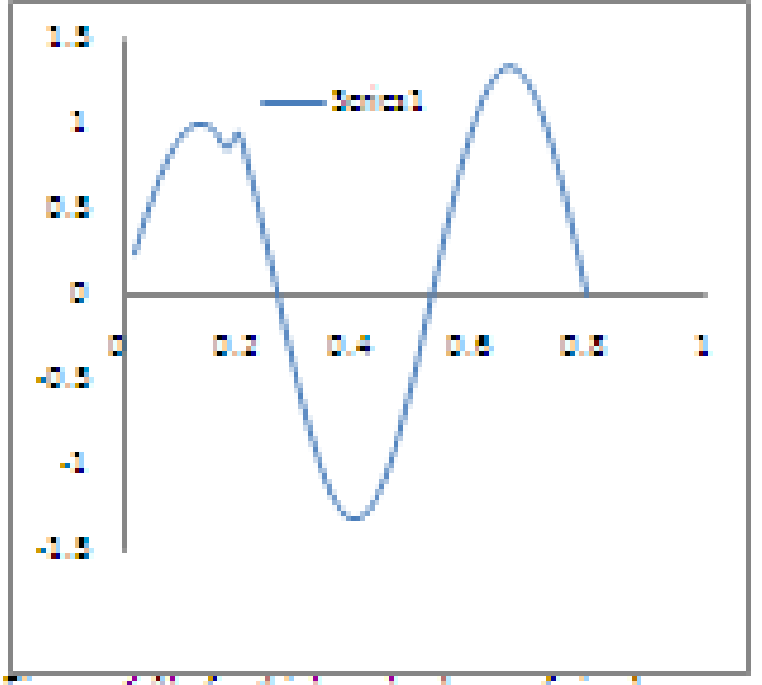

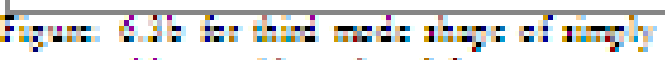

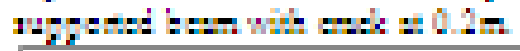

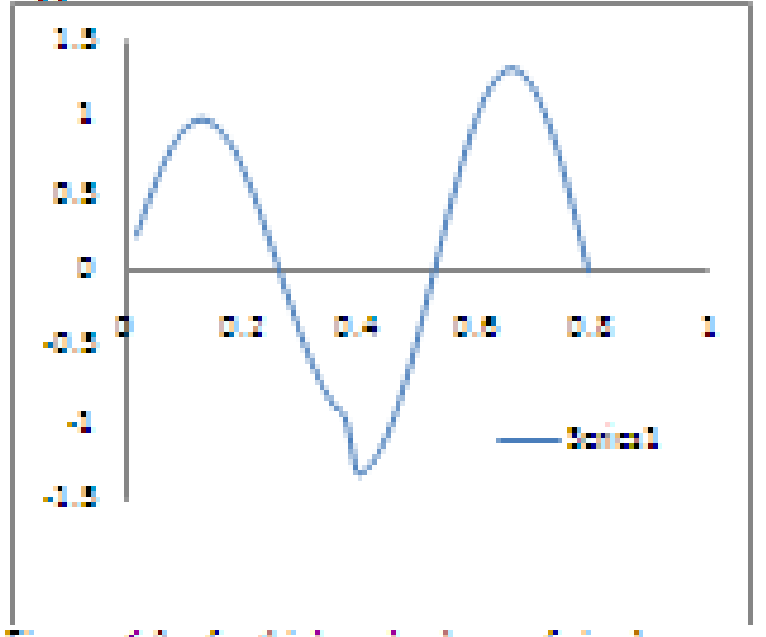

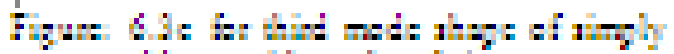

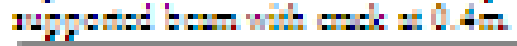

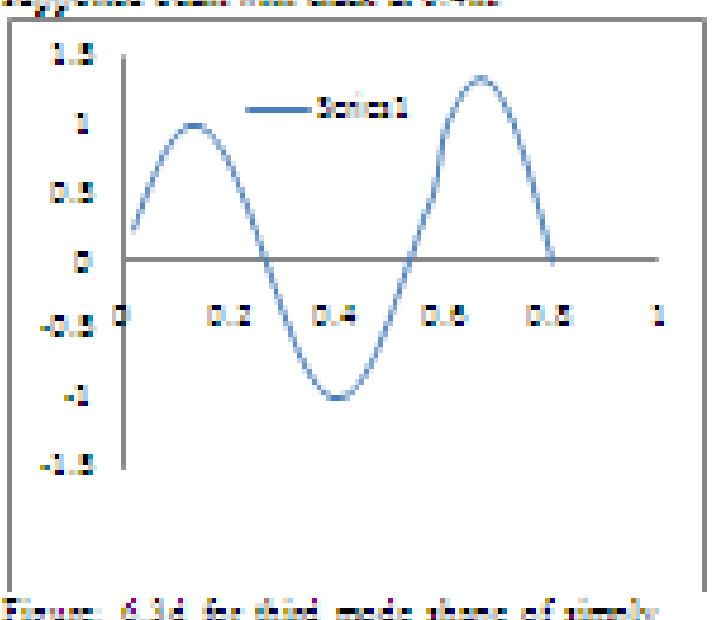

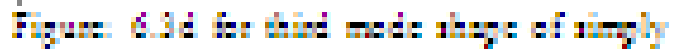

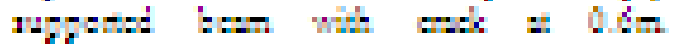




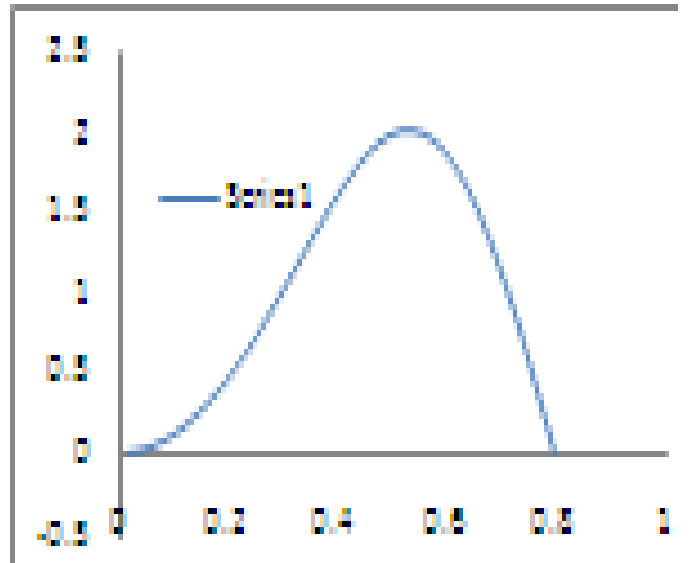

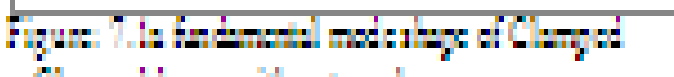

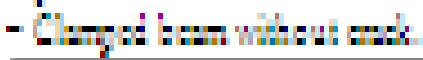

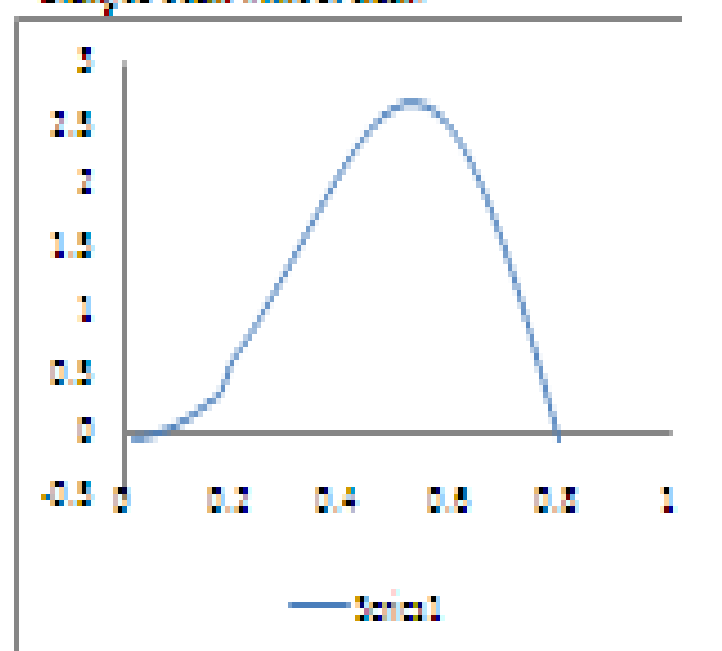

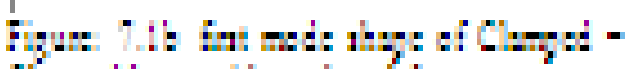

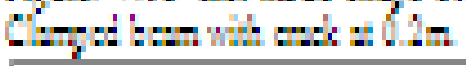

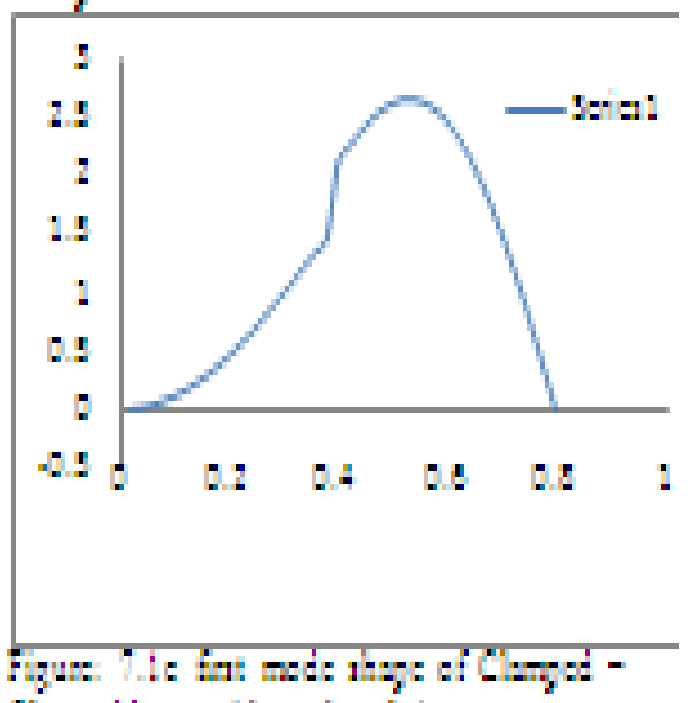

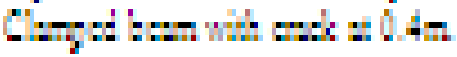

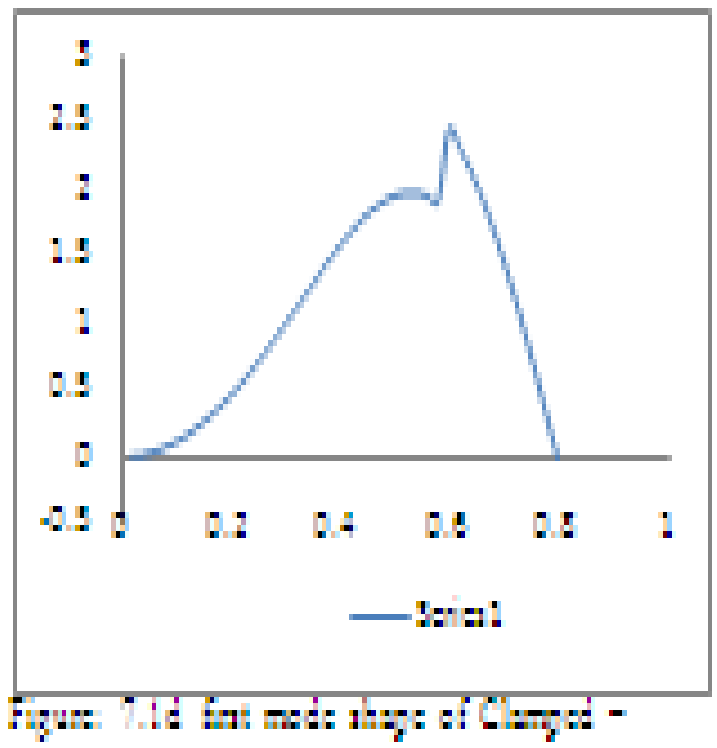

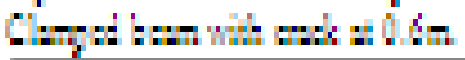

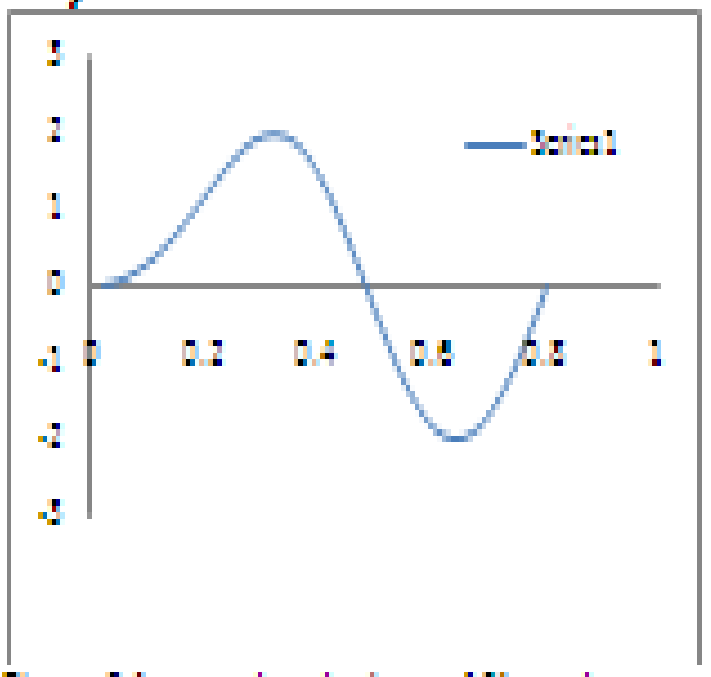

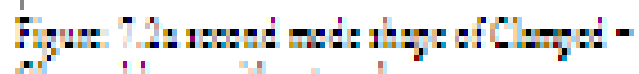

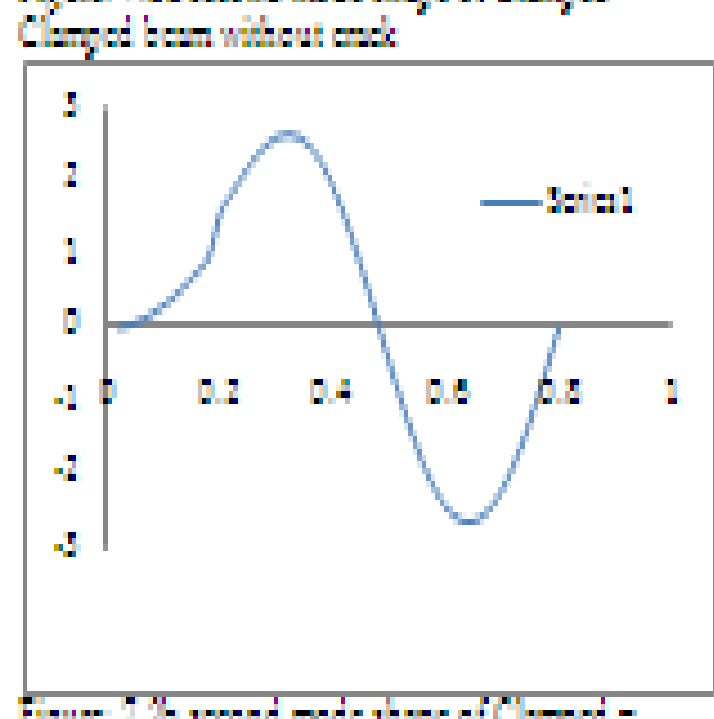

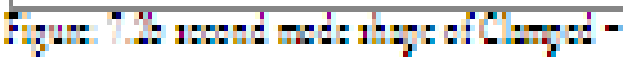

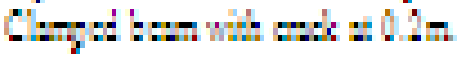



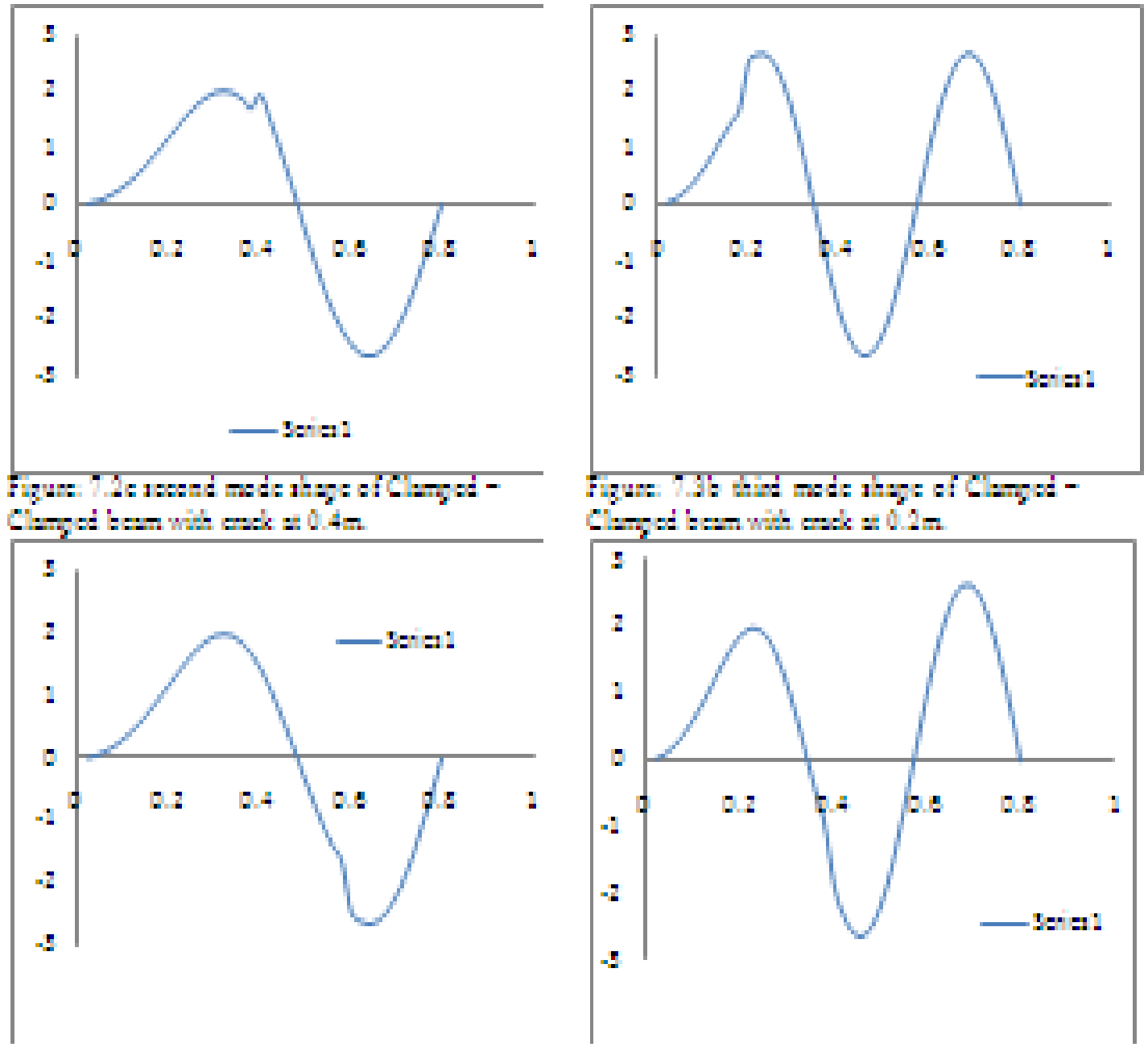

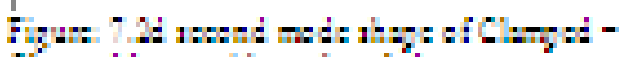

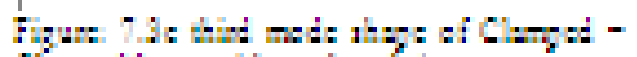

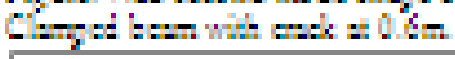

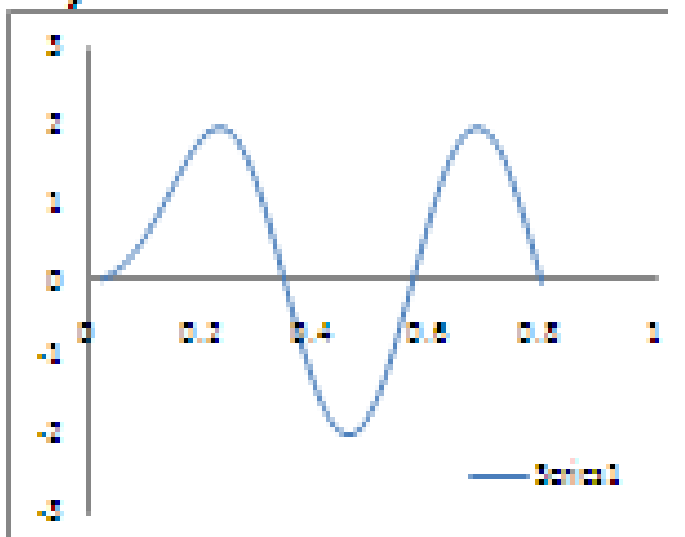

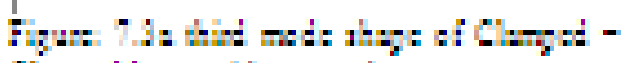

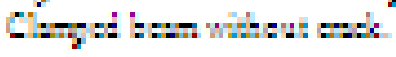

\section{I) Exprimadita}

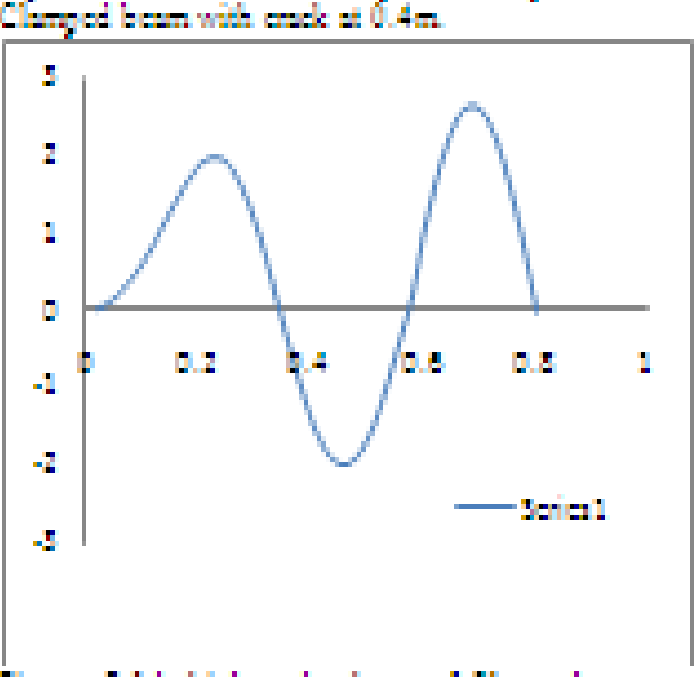

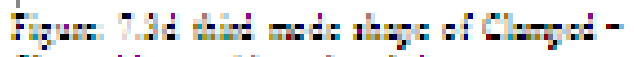

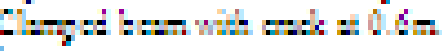

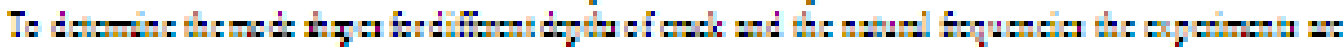

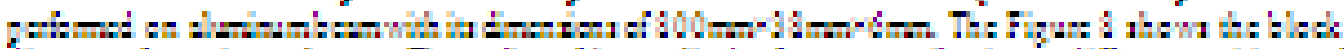

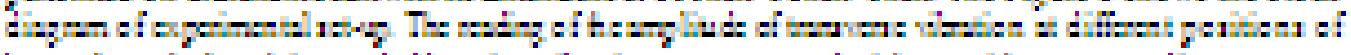

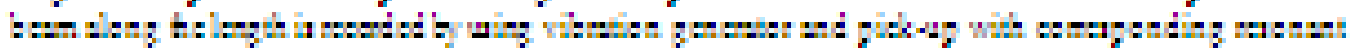
Stpuear 


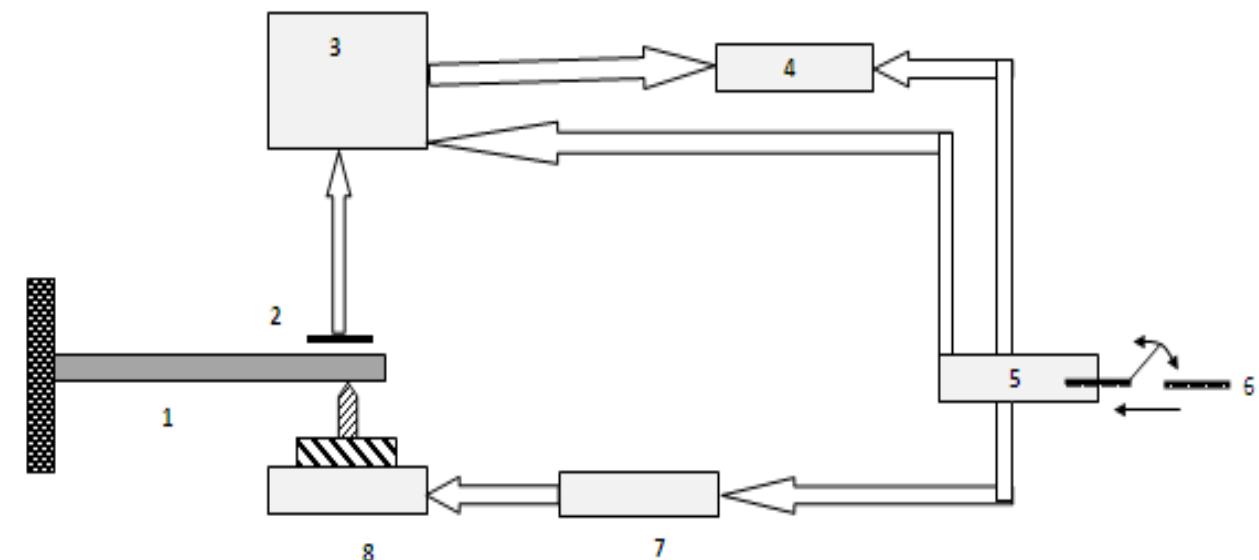

1. Cantilever beam, 2. Vibration Pick-up, 3. Amplifier, 4. Vibration indicator,

5. Distribution box, 6. Power supply, 7. Power amplifier, 8. Vibration generator

Figure: 8 Schematic block diagram of experimental set-up

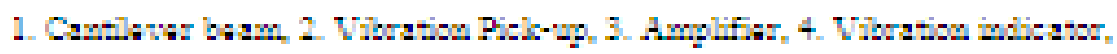

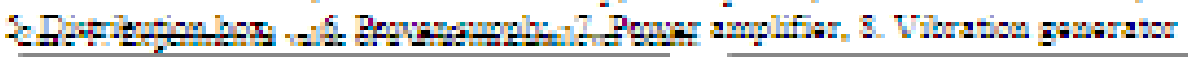

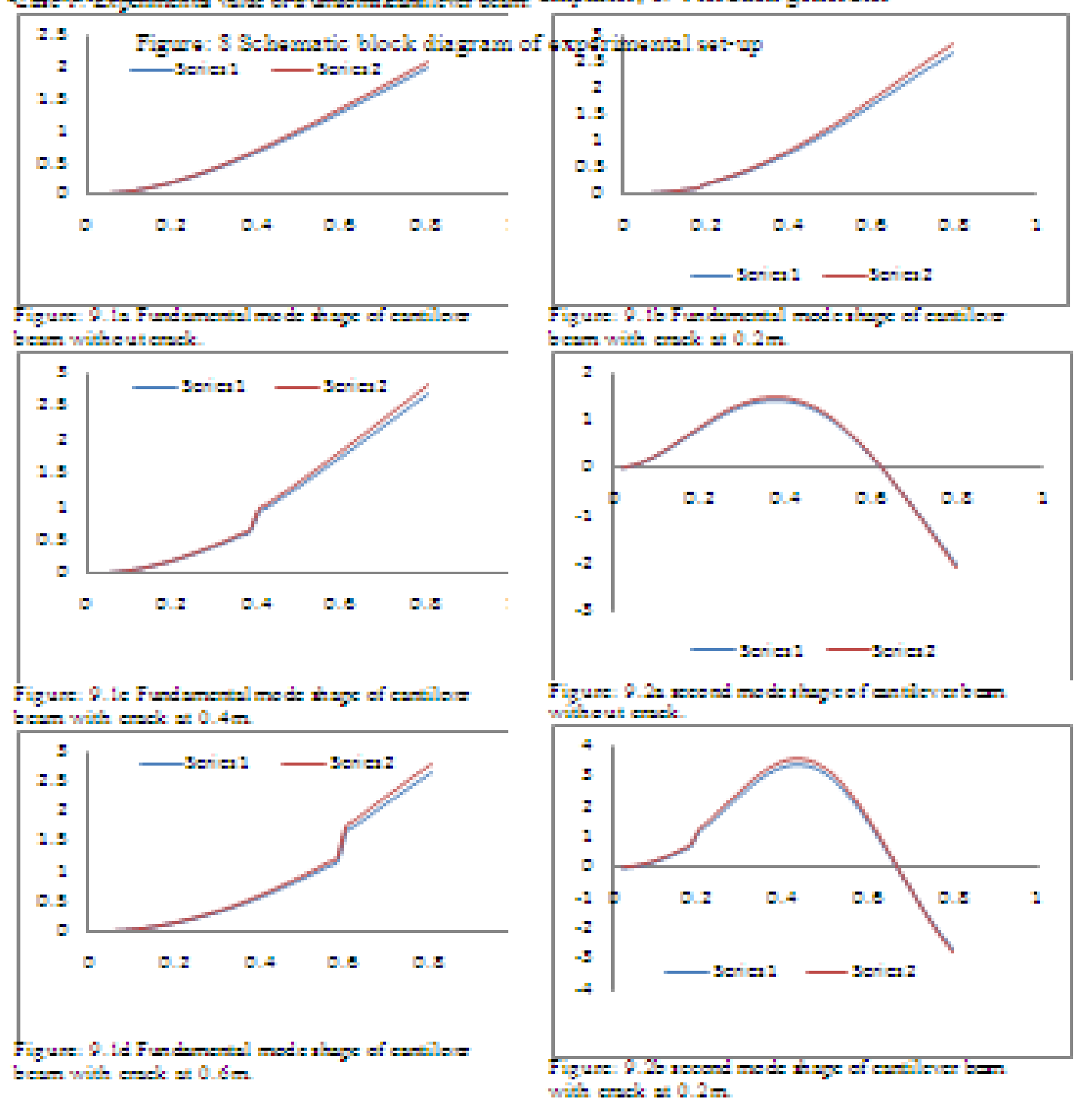




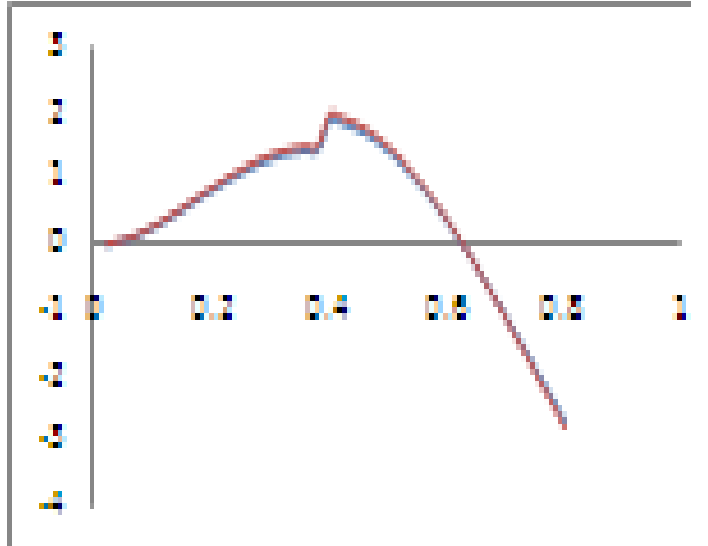

$$
\text { Tag: - Iataz }
$$

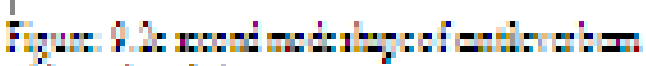

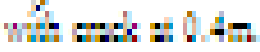

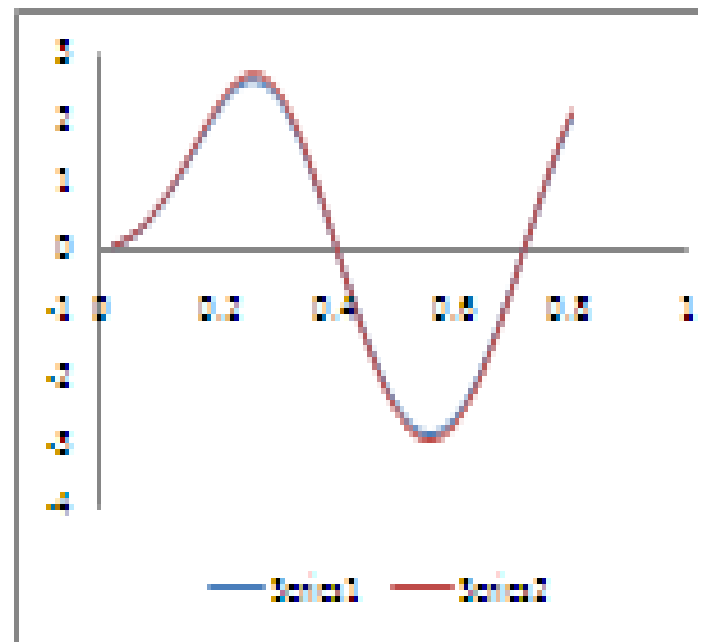

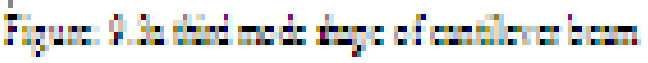

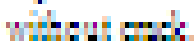

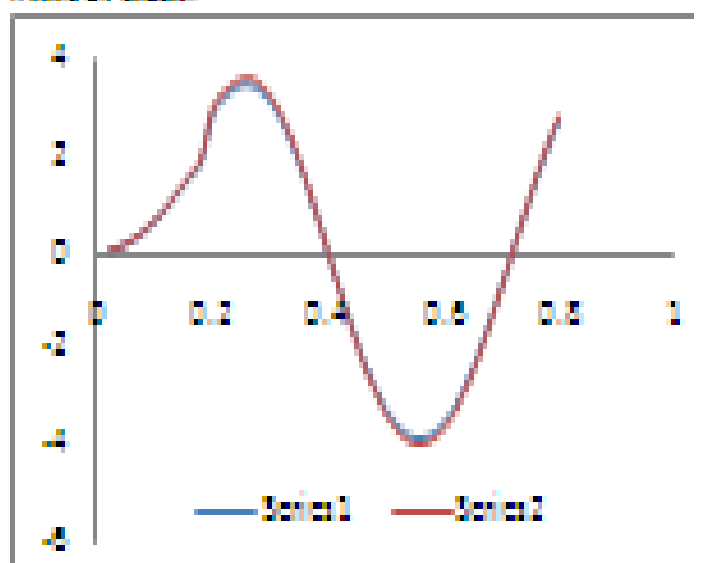

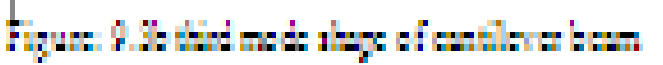
nint and =0.2m

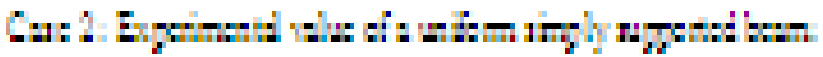

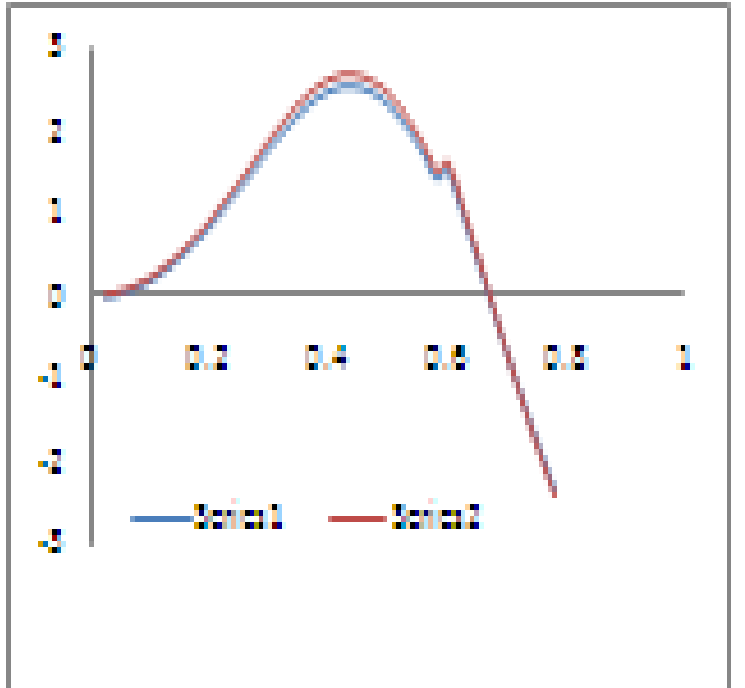

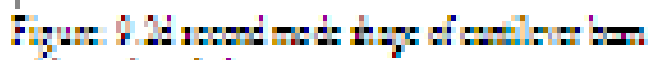

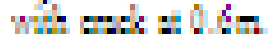

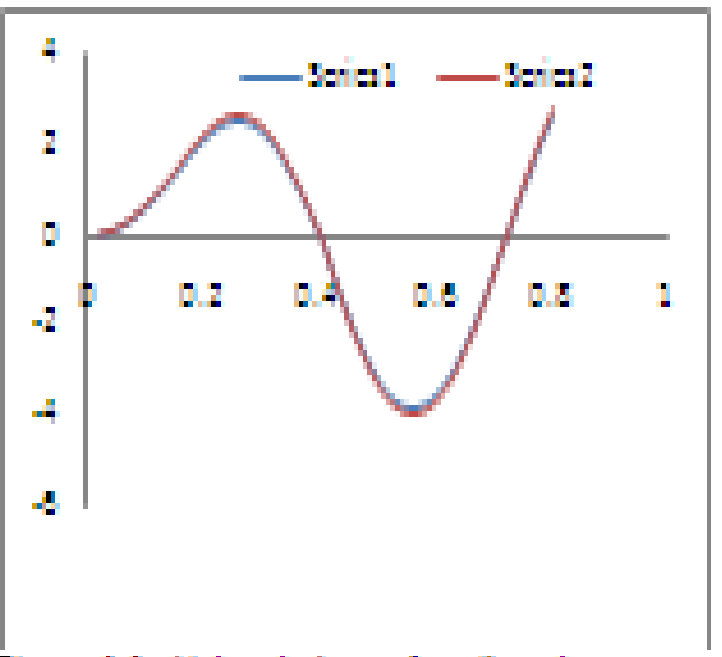

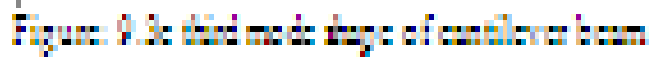
nint and : $0.4 \mathrm{~m}$

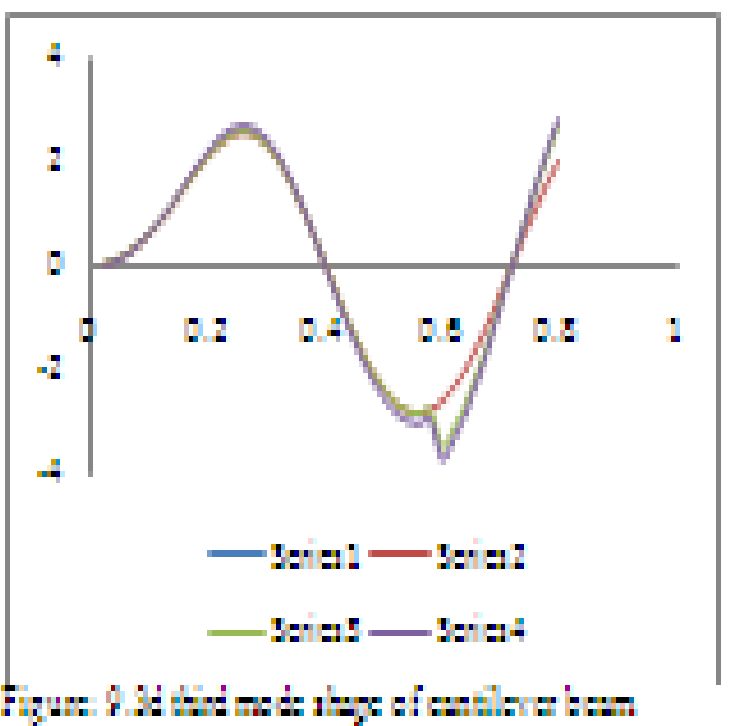

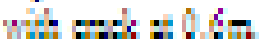




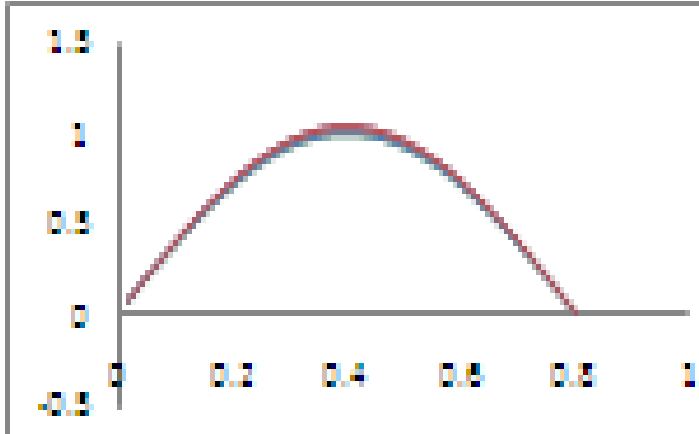

Las - Iaras

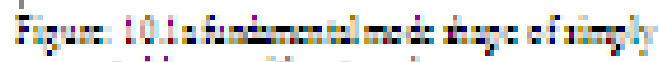

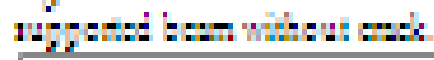

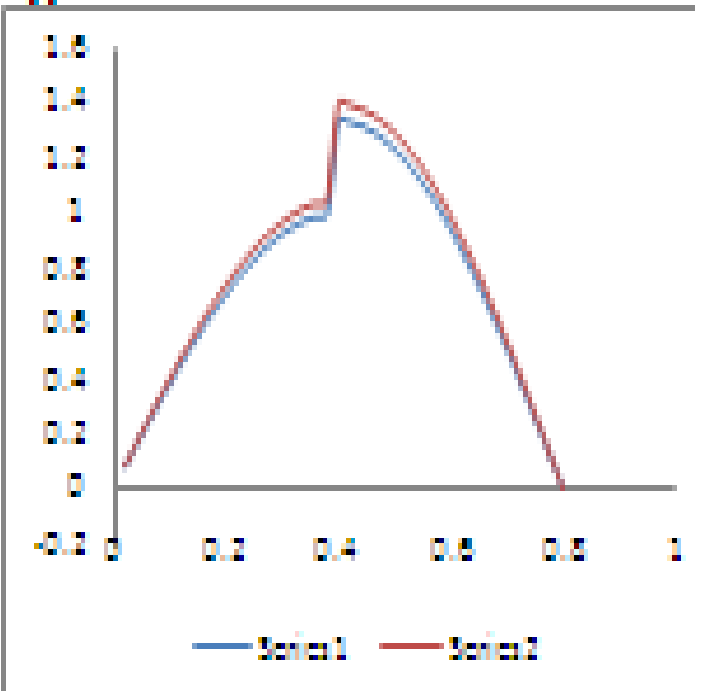

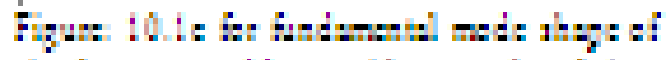

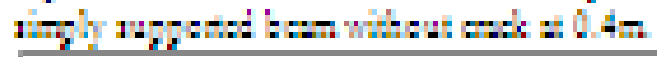

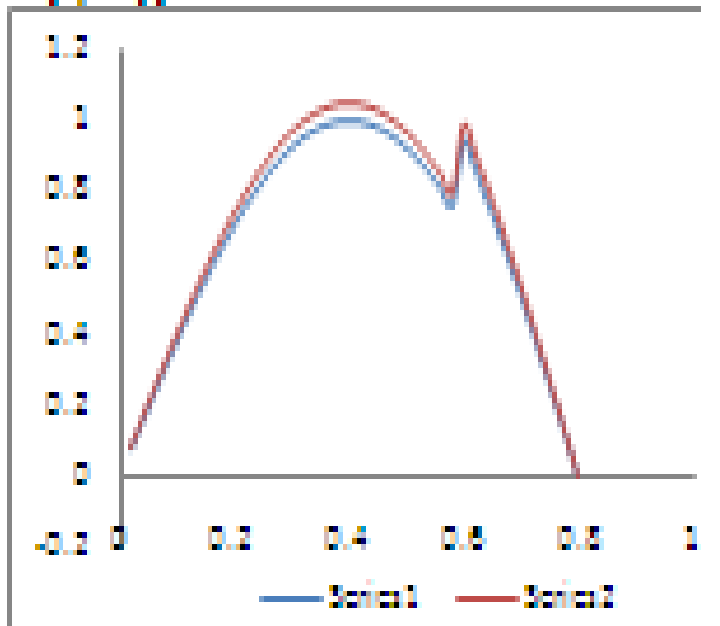

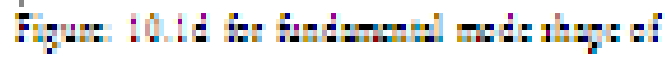

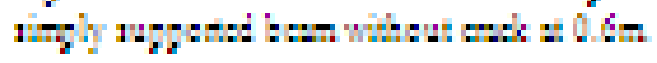

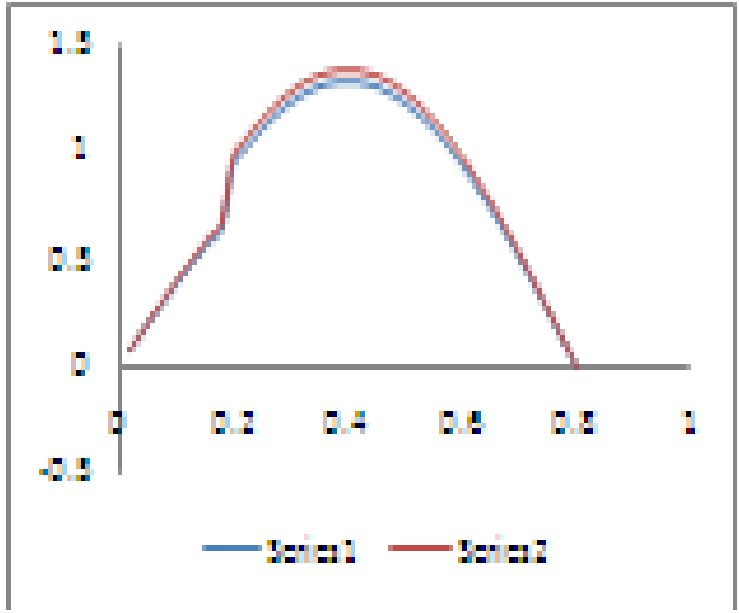

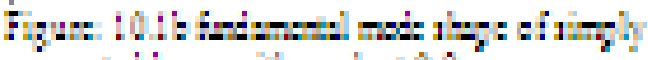

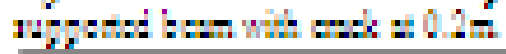

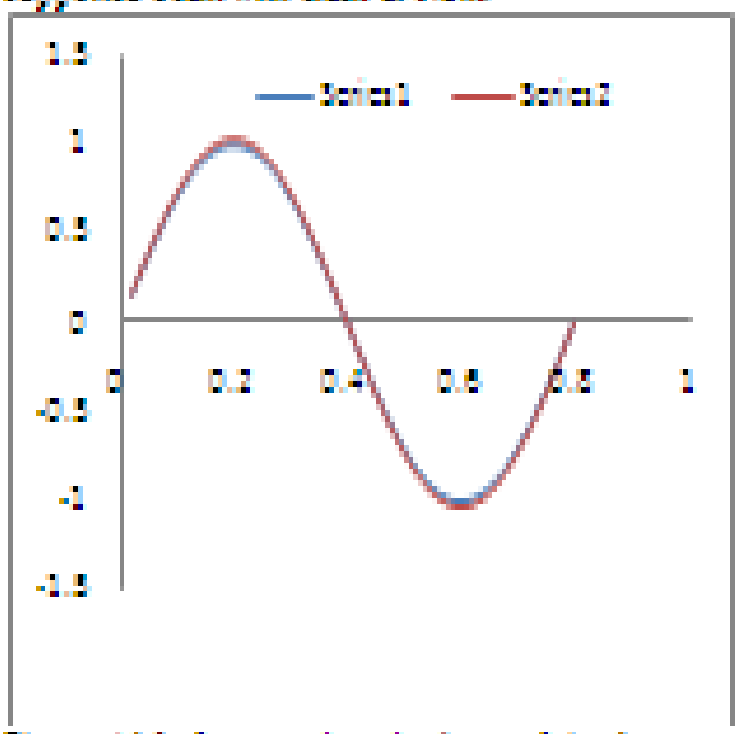

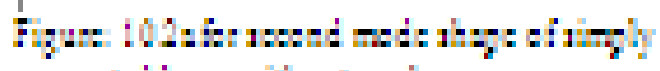

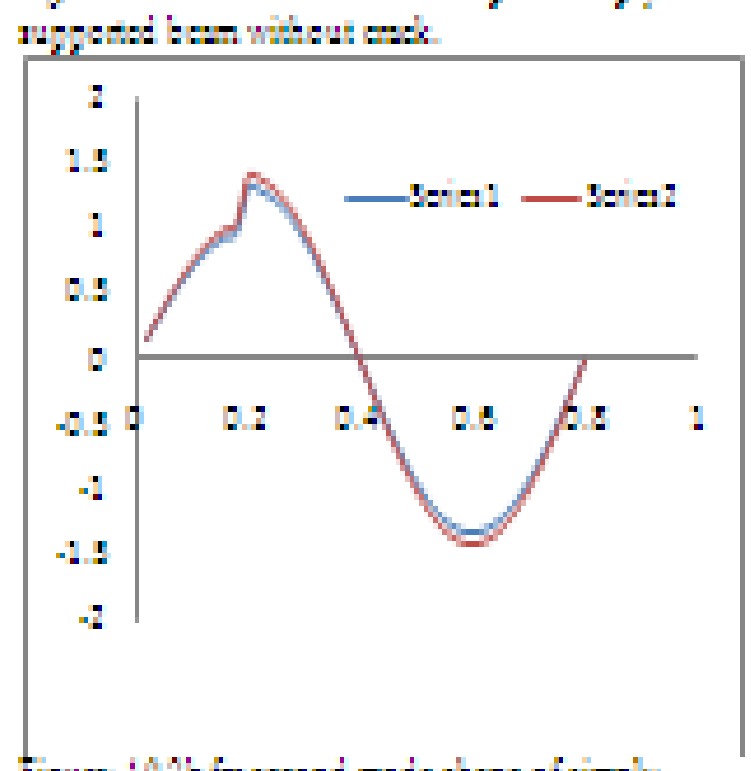

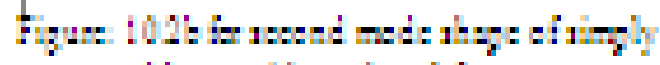

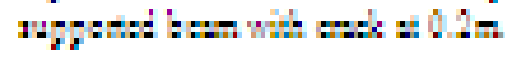



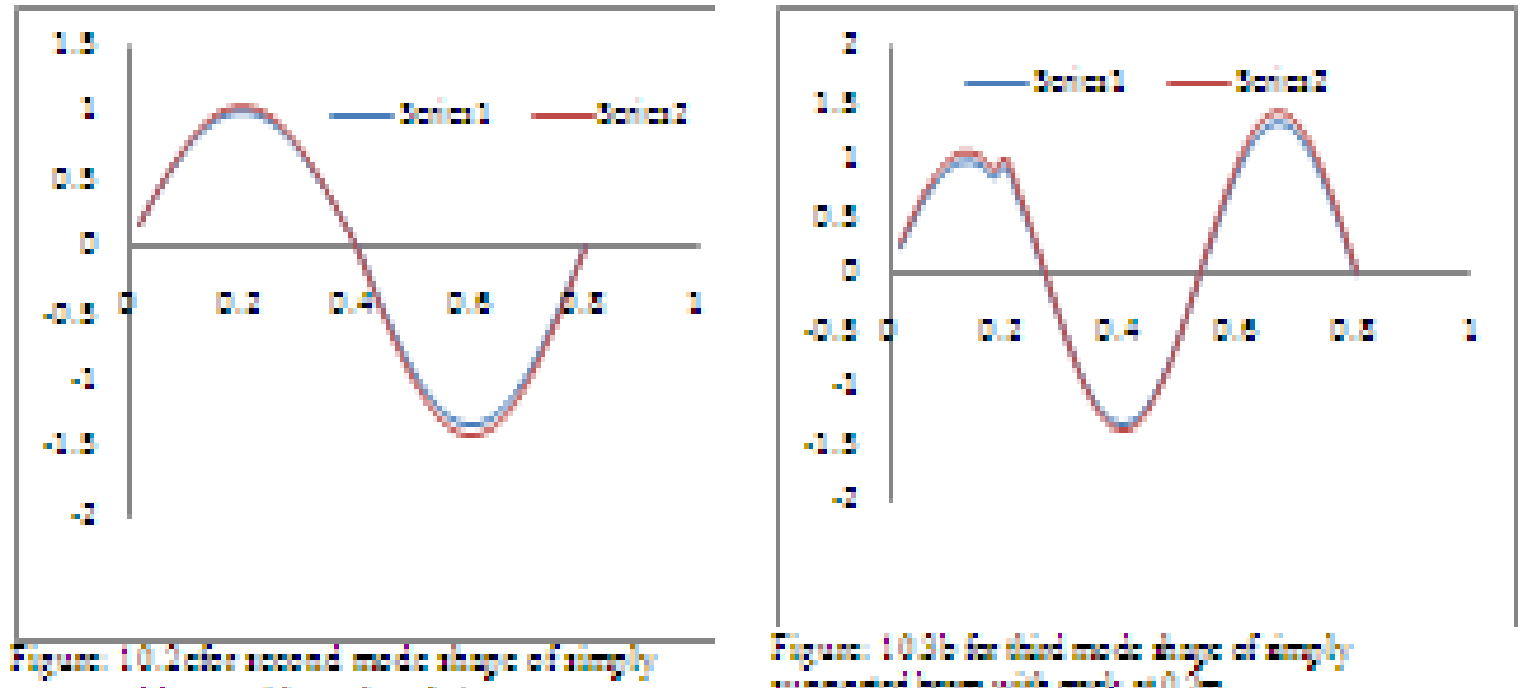

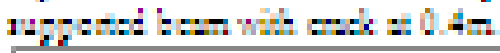

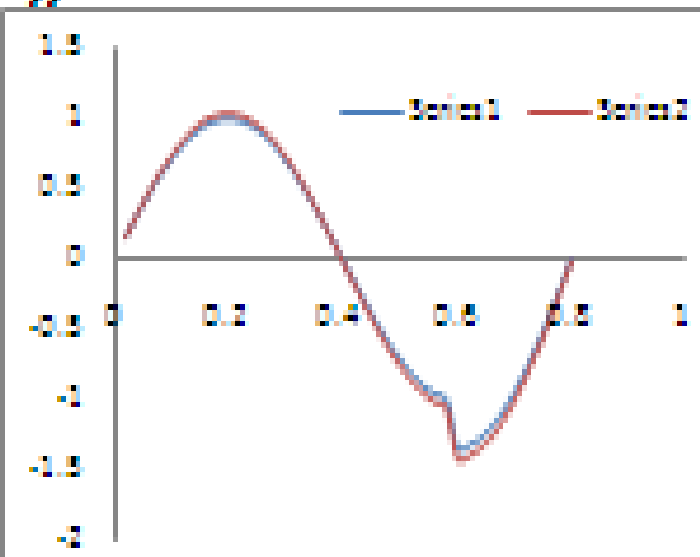

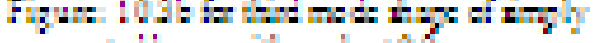

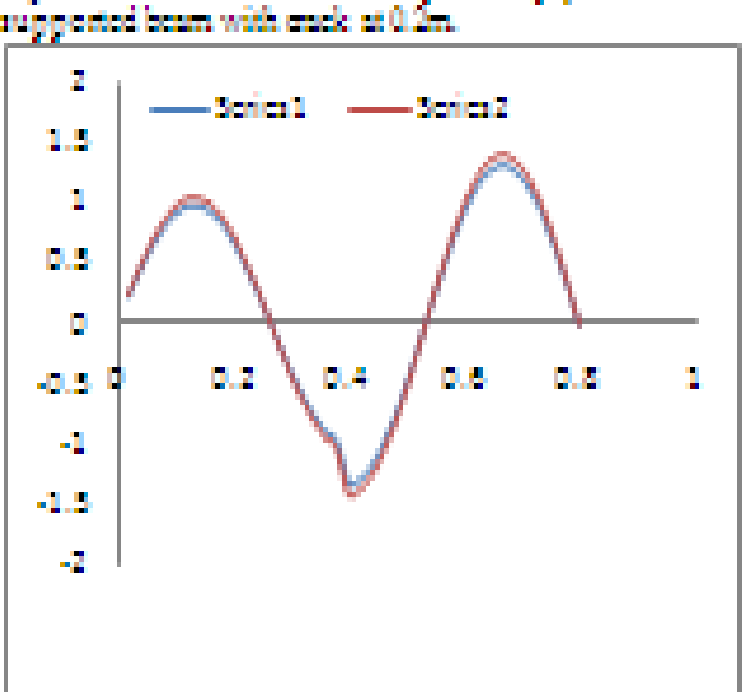

Fipu 102A

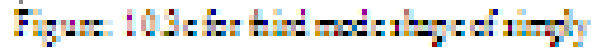

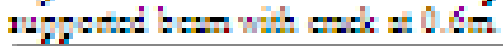
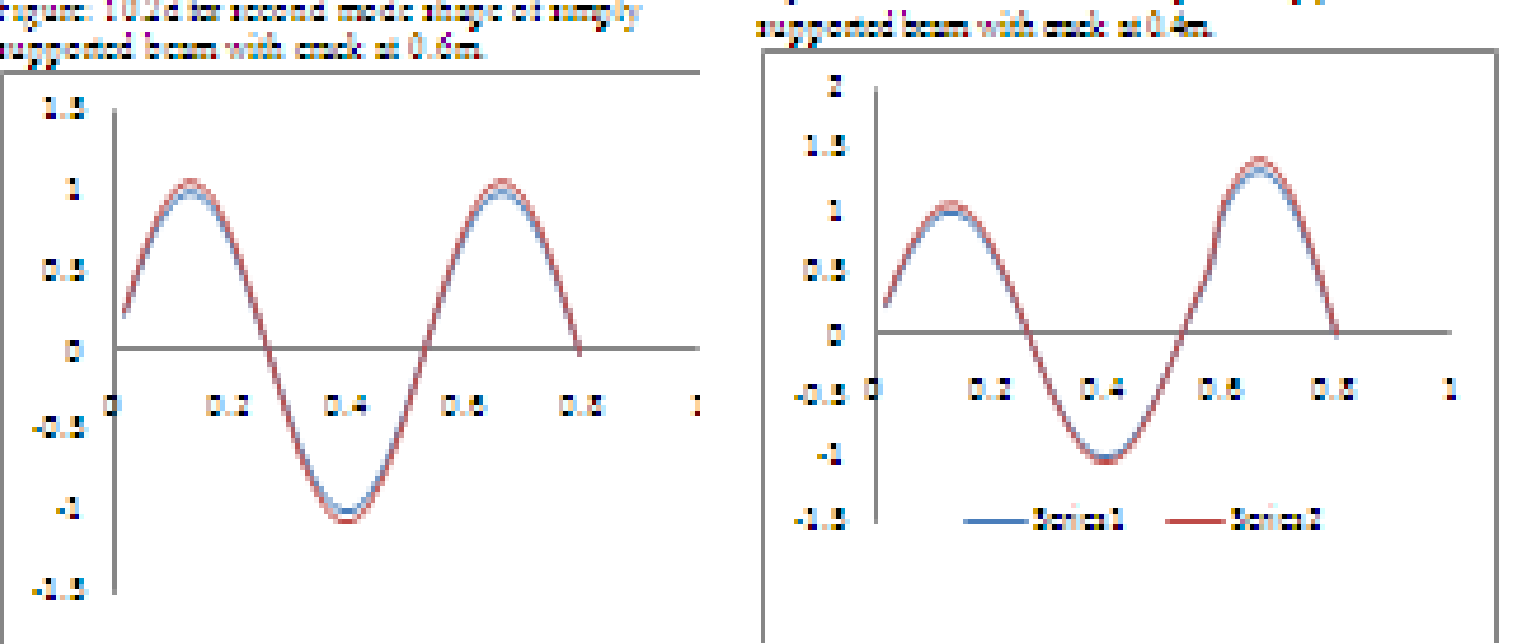

$$
\text { Iar:-Iat: }
$$

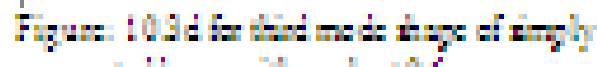

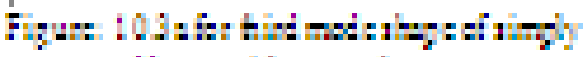

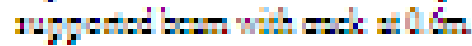

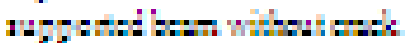

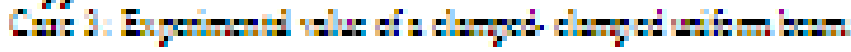




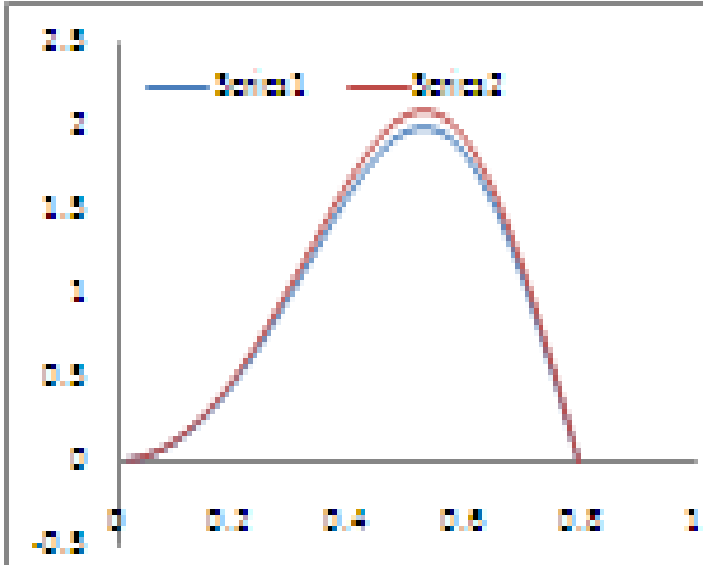

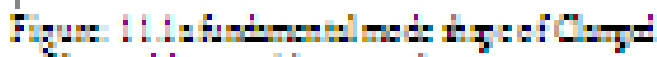

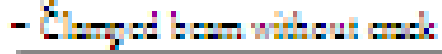

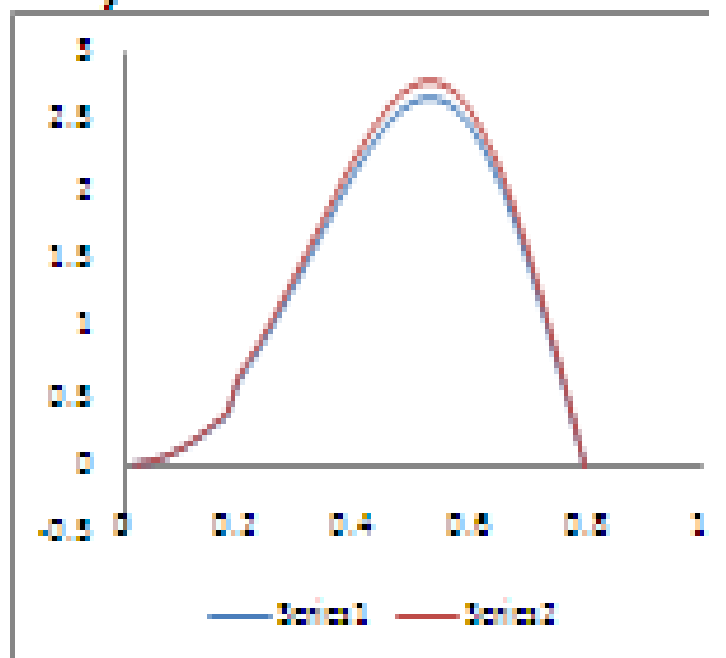

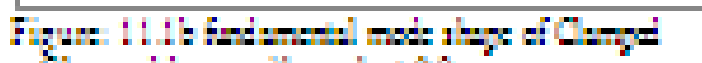

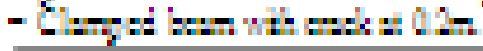

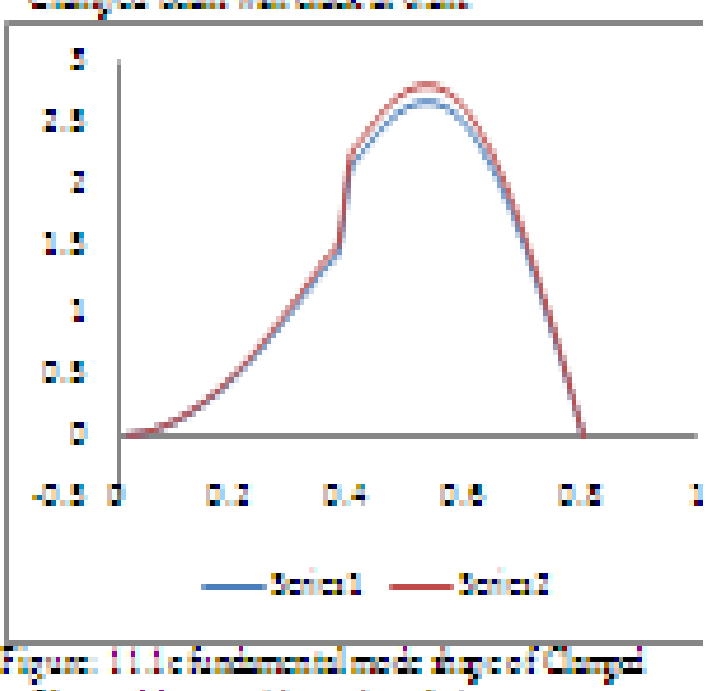

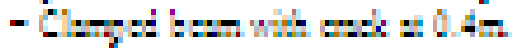

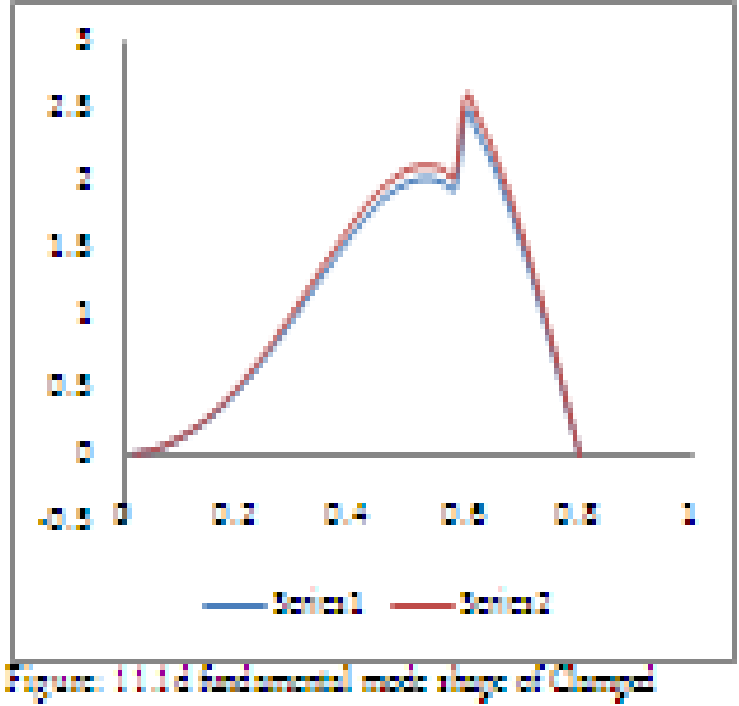

- G:m d:m now at an

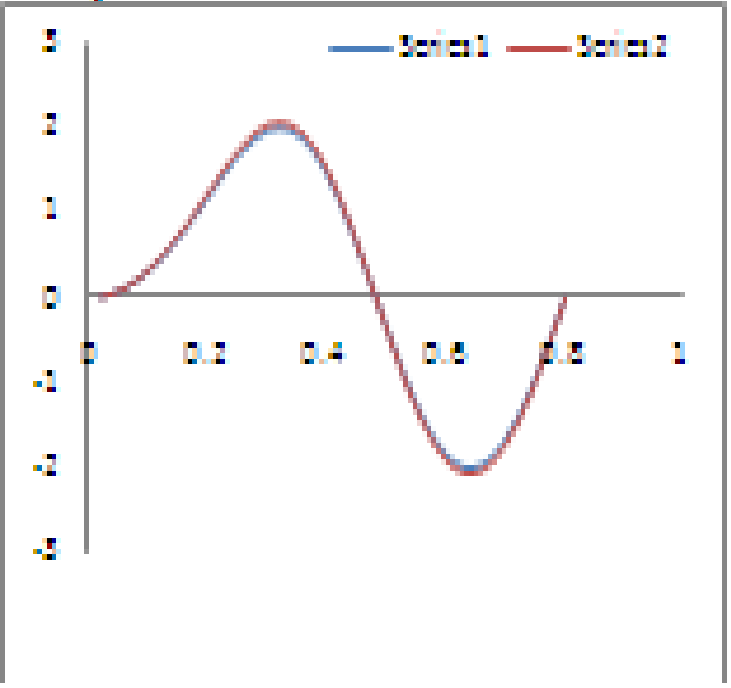

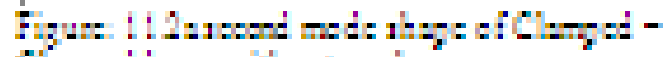

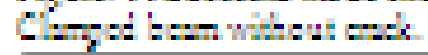

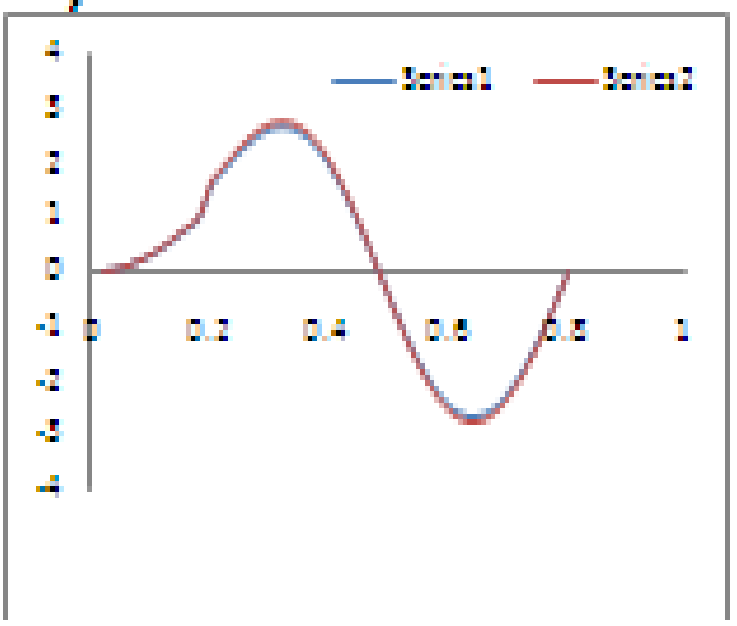

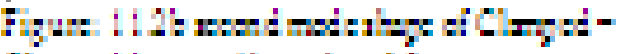

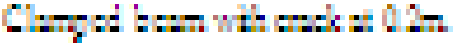



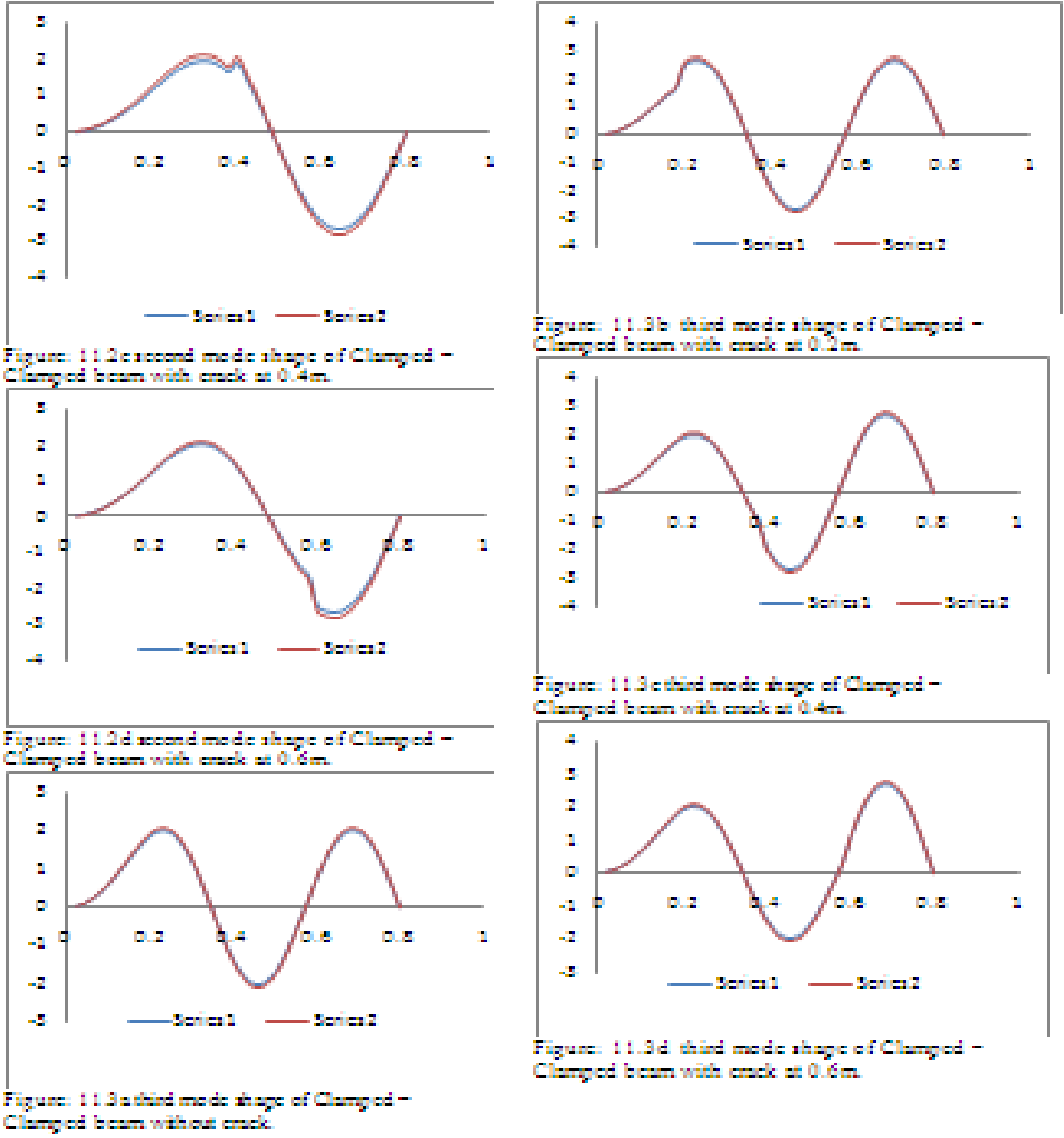

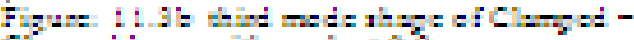

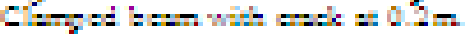

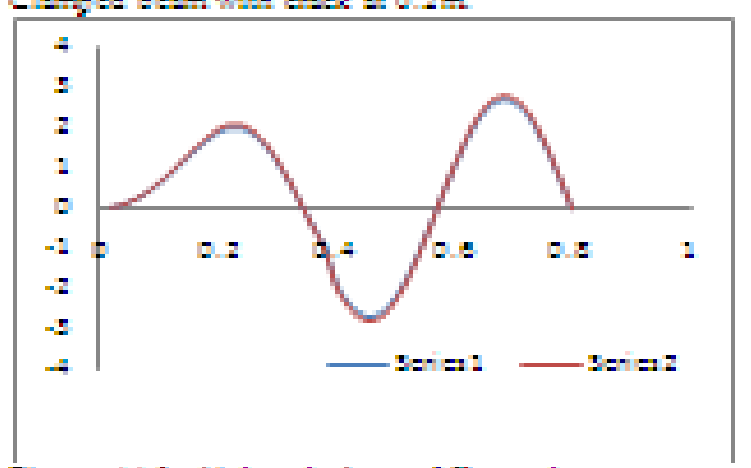

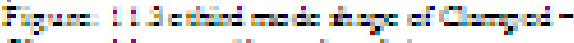

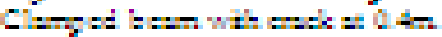

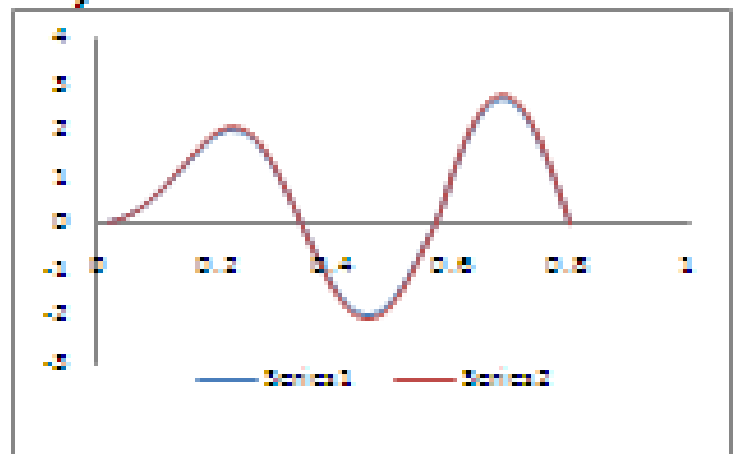

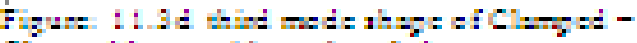

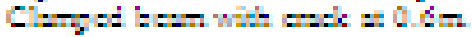

III. Result And Discussions

The results established from theoretical analysis, and experimental analysis are correlated and discussed. Figure 1 presents the geometrical shape, cracked depth and cross-sectional view of the cracked cantilever beam. The theoretical study and analysis of cracked depth with the dimensional measurements are given in figure 2. Analyses of a single cracked cantilever beam subjected to both combine loads (axial forces and bending forces) are given in figure 1 and 3. The results from theoretical analysis for mode shapes of beam with its amplified view at the zone of the crack locale are shown in figures 4- 7. The block diagram of experimental setup is drawn in figure 8. The correlation among theoretical analysis results and experimental analysis results of the cracked beam of cantilever beam, simply supported beam and clamped - clamped beam are displayed in figures 9-11. Experiment have been carried out on aluminum beam specimen of dimensions $800 \mathrm{~mm} \times 38 \mathrm{~mm} \times 6 \mathrm{~mm}$ to find out the mode shapes of uncracked and cracked beam. The results from theoretical analysis and experimental analysis for both cracked and un-cracked beam are correlated and shown in figures 9 11.

\section{Conclusions}

This work addresses the problem of crack detection for a cracked beam using theoretical analysis and experimental analysis. The approach evolved in this paper intimates location, size and depth of the open crack in beam of different end conditions i.e. cantilever beam, clamped-clamped beam and simply supported beam with rectangular cross section. The comparisons of result in both methodologies written above are performed. The 
results of theoretical analysis and experimental analysis are compared and are found to be good correlation in between them. It is concluded that the future work on the problem of fault recognition of a cracked beam can be carried by using more advanced hybrid techniques with the help of finite element method and artificial intelligence technique.

\section{References}

[1]. Al-Said and SamerMasoud, 'Crack identification in a stepped beam carrying a rigid disc', journal of sound and vibration, 300 (35), p. 863-876, March, 2007.

[2]. Andreaus, Ugo and Baragatti, Paolo, 'Cracked beam identification by numerically analyzing the nonlinear behavior of the harmonically forced response', Journal of sounds and vibrations, 330(4), p. 721-742, Feb. 2011.

[3]. Bachschmid,N. Tanzi, E. and Audebert, S. 'The effect of helicoidal cracks on the behavior of rotating shafts', Journal of engineering fracture mechanics,75(3-4), p. 475-488, Feb. 2008.

[4]. Boonya, Prapasorn and Arsit, 'Fault detection and diagnosis process for cracked rotor vibration systems using model based approach', PhD Thesis, Jan. 2009.

[5]. Chondros, T. G. and Labeas, G. N, 'Torsional vibration of a cracked rod by vibrational formulation and numerical analysis', Journal of sound and vibration, 301(3-5), p.994-1006, April, 2007.

[6]. Chondros, T. G. 'Fatigue fracture of the Bjork-Shiley heart valve strut and failure diagnosis from acoustic signature', Journal of theoretical and applied fracture mechanics, 54(2), p. 71-81, Oct. 2010.

[7]. Darpe, Ashish K., 'A novel way to detect transverse surface crack in a rotating shaft', Journal of sound and vibration, 305(1-2), $p$. 151-171, Aug. 2007.

[8]. Das, H. C., and Parhi, D. R., 'Identification of crack location and intensity in a cracked beam by fuzzy reasoning', International journal of intelligent systems Technology and applications, vol.9, No.1, p. 75-95, 2010.

[9]. El-OuafiBahlous, S., Smaoui, H., and El-Borgi, S., 'Experimental validation of an ambient vibration based multiple damage identification method using statistical modal filtering', Journal of sound and vibration, 325(1-2), p. 49-68, Aug.2009.

[10]. Faverjon, B. and Sinou, J. J., 'Identification of an open crack in a beam using an a posteriori error estimator of the frequency response functions with noisy measurement', European journal of mechanics-A/Solids, 28(1), p.75-85, Jan. 2009.

[11]. Gardoni, Paolo, 'Adaptive reliability Analysis of reinforced concrete bridges using nondestructive testing', Dissertation, May, 2010 .

[12]. Kim, Do-Gyoon and Lee, Soon-Bok, 'Structural damage identification of a cantilever beam using excitation force level control', Journal of mechanical systems and signal processing, 24(6) p.1814-1830, Aug.2010.

[13]. Kumar, Chandan and Rastogi,Vikas, 'A Brief review on dynamics of a cracked rotor', International journal of rotating machinery, 2009, p.1-6, Jan. 2009.

[14]. Lu, Z. R., and Law, S. S., 'Dynamic condition assessment of a cracked beam with the composite element model', International journal of mechanical systems and signal processing 23(2), p. 415-431, Feb. 2009.

[15]. Paris, P. C., Tada, H. and Irwin, G. R. 'The stress analysis of cracks hand book', Del Research Corpration, Hellertown, Pennsylvanian, 1973 .

[16]. Qiao,Pizhong and Cao,Maosen, 'Waveform fractal dimension for mode shape-based damage identification of beam-type structures', International journal of solids and structures, 45 (22-23), p.5946-5961, Nov. 2008.

[17]. Shekher, A. S. and Prabhu, B. S. 'Crack detection and vibration characteristics of cracked shaft', Journal of Sound and Vibration, Vol.157, p.375-381, 1992.

[18]. Singh, S. K. and Tiwari, R., 'Identification of a multicrack in a shaft system using transverse frequency response,' Journal of Mechanism and machine theory, 45(12) p.1813-1827, Dec. 2010.

[19]. Xiang, Jiawi, Chen, Xuefeng, Mo, Qiuyun and He, Zhengjia, 'Identification of crack in a rotor system based on wavelet finite element method', journal of finite elements in analysis and design, 43(14), p.1068-1081, Oct. 2007.

[20]. Yan, Wang-Ji, Ren, Wei-Xin and Huang, Tian-Li, 'Statistic structural damage detection based on the closed-form of element modal strain energy sensitivity', Mechanical Systems and Signal Processing, 28, pp. 183-194, 2012.

[21]. Zhong, Shuncong and Oyadiji, S. Olutunde, 'Detection of cracks in simply -supported beams by continuous wavelet transform of reconstructed modal data', Journal of computers and structures, 89(1-2), p.127-148, Jan. 2011.

[22]. Zhu,X.Q. and Law, S. S., 'Wavelet-based crack identification of bridge beam from operational deflection time history', International journal of solids and structure, 43(7-8), p.2299-2317, April, 2006. 